\title{
Measuring the Isolation of Research Topics in Philosophy
}

\author{
Pei-Shan $\mathrm{Chi}^{1}$, Stijn Conix ${ }^{2}$ \\ ${ }^{1}$ peishan.chi@kuleuven.be \\ ECOOM, KU Leuven, Naamsestraat 61, 3000 Leuven, Belgium \\ ${ }^{2}$ stijn.conix@kuleuven.be \\ Centre for Logic and Philosophy of Science, Institute of Philosophy, KU Leuven, Vesaliusstraat 2, 3000 \\ Leuven, Belgium
}

\begin{abstract}
Various authors have recently argued that certain parts of academic philosophy are highly isolated from other fields of academic research. The central aim of this paper is to go beyond philosophical arguments, and empirically test whether this is indeed the case. More specifically, we investigate whether domains of Core Philosophy, like metaphysics and epistemology, are more isolated than Philosophy of Science and Philosophy of Value Issues. To do this, we collected 2,369 WoS indexed papers divided into 17 Philpapers topics from these three kinds of philosophy, and used 11 indicators to measure their isolation. The results show that both Philosophy of Science and Philosophy of Value Issues are less isolated than Core Philosophy. In addition, general topics in Philosophy of Science and Philosophy of Value Issues tend to be more isolated than applied topics. These results suggest that the isolation of philosophy could be alleviated by shifting the priority from Core Philosophy to applied Philosophy of Science and Value Issues.
\end{abstract}

Keywords

Core Philosophy, Philosophy of Science, Philosophy of Value Issues, Academic Isolation, Citation Impact, Scholarly Collaboration

\section{Note: this is the submitted (not yet accepted) version of this paper. Once the} paper is accepted, we will link this draft to the published version.

\section{Introduction}

Various academic philosophers have recently expressed worries about the value of some of the current work in their discipline (e.g. Chalmers 2015; Dietrich 2011; Higgins and Dyschkant 2014; Kitcher 2011). One major source of these worries is the seeming lack of progress philosophy has made. Philosophers have been engaged in investigating the same 'big questions' for well over two millennia, but have not come close to any consensus for most of them. Questions about the nature of knowledge, truth, morality and the life worth living are as much a philosophical battleground today as they were in Ancient Greece (Chalmers 2015; Dietrich 2011).

That is not to say that academic philosophy makes no progress at all. Even if philosophers have failed to agree on what, for example, knowledge is, they have developed a wide range of competing sophisticated theories on the subject. Rescher (1985, p.207; cited in Plant 2012) calls this progress in "philosophical technology": Even if philosophers never reach consensus about the questions they try to answer, they do add ever more positions, arguments, counterarguments, distinctions and counterexamples to the debates about these questions. In 
this respect, philosophy differs from many other fields of academic research, like biology or physics, where important questions are occasionally answered and used as building blocks for further research. This contrast with the natural sciences brings out what David Chalmers (2015) calls the 'glass half empty view' about progress in philosophy: philosophy makes some technical progress, but not in answering the big questions it ultimately aims to answer, and not at the same rate as many other fields of academia.

A second and related source of worry causes some philosophers to consider the glass even less than half-full. While it is undeniable that philosophers continue to add clever and sophisticated views across a range of topics, some worry that much of this progress consists in technicalities with little purpose and no audience outside of the small group of philosophers working on those technicalities. Philip Kitcher, quoting Dewey (2004, p.315), worries that philosophy is becoming a "sentimental indulgence of the few". In a similar vein, Daniel Dennett (2006, p.39) writes that "many projects in contemporary philosophy are artifactual puzzles of no abiding significance". Colorfully building on Dennett's worries, Boghossian and Lindsey (2017, p.64) write that research in the discipline "twiddles away and seriously entertains the hyper-esoteric and inconsequential" generally "buttressed by the tendency of philosophers to engage in a game of intellectual peekaboo with ideas that do not merit serious considerations". "To attend a philosophy conference", they write, "is to marvel at the obscurity and irrelevance of what's become of the discipline" (p. $64-65$ ).

Boghossian and Lindsey connect these worries about the value of academic philosophy to the isolation of philosophical research. They remark (p. 65) that "it's almost as if philosophers have forgotten how to speak to people not just outside their discipline, but also outside their niche". Many others echo the claim that the root of the problems discussed above lies in the isolation of philosophical specialisms (Frodeman 2013; Cherry 2017; Higgins and Dyschkant 2014; Kitcher 2011). ${ }^{1}$ Ladyman (2017), for example, complains that much work in contemporary metaphysics on a subject like time completely disregards physicists' work on this topic. Similarly, Higgins and Dyschkant (2014, p. 376) remark in the context of case study of analytic metaphysics that "each discussion becomes increasingly specialized, the resulting theories, conceptual frameworks, and common knowledge become increasingly alien to other academics".

Pessimistic as this view of philosophy as a cluster of isolated specialisms may seem, it warrants optimism in that it suggests a straightforward solution: philosophers should, as much as possible, try to connect to other research within philosophy and in other fields of academia (see also Fehr and Plaisance 2010; Plaisance 2020). And indeed, most of the critics cited above point out that some parts of philosophy already do this. Kitcher (2011), for example, argues that large parts of 'core areas of philosophy' (i.e. metaphysics, epistemology, philosophy of language and philosophy of mind; $\mathrm{CP}$ henceforth) tend towards isolation, but points to two other types of philosophy that are far less isolated. First, some philosophy takes other academic disciplines as its subject, and often engages extensively with those fields. For example, philosophy of physics typically engages with physics. Second, some philosophical work focuses on questions about values and societal issues, and often engages with other research relevant to these issues. For example, philosophers thinking about the permissibility of abortion

\footnotetext{
${ }^{1}$ We follow Higgins and Dyschkant in using the term 'isolation' for this. Others have used 'insular' (e.g. Frodeman 2013), 'esoteric' (e.g. Boghossian and Lindsey 2017), 'self-involved' (Pigliucci 2017) and 'intradisciplinary siloing' (e.g. Wilson 2017) to discuss the same problem.
} 
are often engaged with medical work on abortion. Kitcher argues that these two types of philosophy - call them 'Philosophy of Science' (PoS henceforth) and 'Philosophy of ValueIssues (PoVI henceforth)' - are far less vulnerable to worries about isolation and a seeming lack of value.

Many others follow Kitcher's claims, and argue that some parts of philosophy engage frequently with other disciplines of science, or with policy makers (Cherry 2017; Higgins and Dyschkant 2014; Ladyman 2017). Thus, just like there is widespread belief that some parts of philosophy are self-involved and isolated, there is widespread belief that this is not equally the case for all subfields of philosophy. In particular, PoS and PoVI are often assumed to be less isolated than CP. If true, this has far-reaching implications. CP currently dominates academic philosophy, while PoS and PoVI are what Kitcher (2011) calls 'peripheral' areas. These peripheral areas draw less funding, fewer students, and take up fewer faculty positions and a less prominent position in philosophy degrees. If the hypothesis of Kitcher and others is true, there would be good reasons to turn philosophy 'inside out' (Kitcher 2011), and move the peripheral areas (PoS and PoVI) into a more prominent position at the expense of $\mathrm{CP}$.

Baumann (2013) points out that claims concerning the isolation of different areas of philosophy are empirical, and thus require empirical support instead of philosophical arguments. There are multiple bibliometric studies that indirectly provide such support. First, some studies show that particular areas of philosophy are isolated. Higgins and Dyschkant (2014) present evidence that analytic metaphysics tend to only cite each other, and Higgins and Smith (2013) show that philosophical research on ontology is isolated. Similarly, Kreuzman (2001) shows that philosophy of science is isolated from epistemology, even though their subject areas overlap extensively. Buonomo and Petrovic (2018) show, by means of a series of maps of analytic philosophy based on co-citation, that research topics in analytic philosophy have become more isolated since 2005 .

Second, a small number of studies show that at least PoS is well-connected to the sciences. McLevey et al. (2018) analyse the disciplinary boundaries between PoS and the sciences by looking at citation patterns, and find that philosophers of science regularly publish in and get cited by science journals. Philosophers of science also reported extensive collaboration and interaction with scientists, and even that it is an obligation for PoS to impact science (Plaisence et al. 2019). However, a survey among philosophers specializing in various CP fields reported similarly strong and widespread support for interdisciplinary approaches to philosophy (Tiberius 2017).

While these studies suggest that it is plausible that CP is more isolated than PoS and PoVI, they are far from conclusively showing this. This is because these studies focus on one particular debate or area of philosophy, and do not allow for comparisons between different areas. The aim of this paper is to fill this gap and investigate whether, and to what extent, PoS and PoVI are more or less isolated than CP. To do this, we selected cases from different philosophical subfields, and used bibliometric methods to investigate the extent to which these are isolated from other parts of academic research.

This question has more than just intellectual import. The American Philosophical Association - the largest professional organization in Philosophy - had almost 5000 employed members in 
2018. ${ }^{2}$ In addition, many new Bachelors, Masters and Doctores in philosophy graduate each year (in the United States, for example, respectively 7398, 957 and 454 in 2014). ${ }^{3}$ Even without including philosophers and students outside the US in these numbers, it is clear that a large amount of state funding and educational effort is invested in philosophy. If, as Kitcher suggests, the prestigious and dominant core areas are far more isolated than 'peripheral' areas, these funds and educational efforts may be misdirected. ${ }^{4}$

\section{Hypotheses}

To investigate whether certain parts of philosophy are more isolated than others, we need to divide the field of philosophy into smaller parts. As noted above, we will rely in the first place on Kitcher's distinction between CP, PoS and PoVI. However, this three-part classification is not fine-grained enough to capture the clusters of research that, on the basis of our experience of the field, we expect to be self-involved and isolated. Hence, we follow Boyack and Klavan's (2017a) suggestion to take 'research topics' as the unit of analysis. ${ }^{5}$ Research topics are collections of documents "with a common focused intellectual interest, such as work on a specific research problem" (Klavans and Boyack 2017a, p. 1159). Each such topic has a community of about a hundred researchers working on it. In our study, these topics are collections of documents that are devoted to a single problem or question, that are very likely connected through citation, and produced by a well-connected community of researchers.

On the basis of Kitcher's (2011) and the literature discussed above, then, we expect the following hypotheses to hold:

A) Philosophy of Science is less isolated than Core Philosophy: it should be expected that, on average, research topics in $\mathrm{PoS}$ are less isolated than research topics in CP.

B) Philosophy of Value Issues is less isolated than Core Philosophy: it should be expected that research topics in PoVI are, on average, less isolated than research topics in CP.

C) The more PoS and PoVI are like CP, the more isolated they are: It should be expected that philosophical topics from PoS and PoVI are more isolated if they engage less with practical issues relevant to other fields, and focus more on the kind of general questions that CP focuses on. Thus, 'general' topics in PoS and PoVI are expected to be more isolated than 'applied' topics in the same areas.

\section{Methodology}

\section{Selection of research topics}

Philosophical research topics are intellectually homogeneous collections of papers devoted to a single research problem or question. Such research topics are often identified using citation data or co-authorship data (Klavans and Boyack 2017b). However, we already use these data

\footnotetext{
2 https://www.apaonline.org/page/demographics

3 https://www.apaonline.org/page/data

${ }^{4}$ We say 'may be misdirected' as broad relevance (and lack of isolation) is just one way in which philosophical research can be valuable. Some would argue that even philosophy that is highly isolated can be highly valuable in other ways, and we do not mean to argue against this here.

${ }^{5}$ Boyack and Klavans suggest this in the context of determining research priorities. Notice that this is closely related to the subject of this paper, namely, the value of research topics: topics of higher value are those that should receive funding.
} 
to evaluate the isolation of research topics. To avoid circularity, we instead use the publicly available classification scheme designed by Philpapers.org to categorize the philosophical documents it lists.

PhilPapers is a comprehensive index of the research literature in philosophy, with the largest structured bibliography in the field. Its bibliography counts 5,581 categories managed by 814 volunteer editors. ${ }^{6}$ As this classification is actively curated by experts, its categories are unlikely to contain many spurious documents. These categories contain over two million published items in a five-level classification scheme ranging from five main 'Clusters' to 'Subtopics' which typically consist of $15-100$ documents. Inspection of the classification made it clear that only categories at the leaf-level (i.e. Subtopic) approximate the intellectual homogeneity by which we defined research topics. We therefore operationalize the notion of research topic as the collection of documents collected in a leaf category of the Philpapers classification scheme.

Among these 5,581 topics we selected 17 (see Table 1). To enable investigation of the differences between PoS, PoVI and CP (Hypotheses A and B), the topics were distributed evenly between these three kinds of philosophy. To ensure that we could test whether topics from PoS and PoVI are more isolated as they are more like Core Philosophy (Hypothesis C), we relied on the Area-level of the Philpapers classification to select two 'general' and four 'applied' topics in each of these categories. In PoS, general topics were selected from 'General Philosophy of Science', and applied topics from 'Philosophy of Biology' and 'Philosophy of Physics'. In PoVI, general topics were selected from 'Meta-ethics' and 'Normative ethics', and applied topics from 'Applied ethics', 'Philosophy of race, gender, sexuality', and 'Social and Political Philosophy'. The full list of criteria used to select the topics can be found in Appendix A.

Table 1. Initially selected topics in three kinds of philosophy

\begin{tabular}{|c|c|c|c|c|}
\hline General PoS & Applied PoS & $\begin{array}{l}\text { General } \\
\text { PoVI }\end{array}$ & Applied PoVI & $\begin{array}{l}\text { Core } \\
\text { Philosophy }\end{array}$ \\
\hline \multirow{5}{*}{$\begin{array}{l}\text { Incommensurability } \\
\text { in science } \\
\text { The nature of } \\
\text { models }\end{array}$} & Biodiversity & \multirow{5}{*}{$\begin{array}{l}\text { Moral } \\
\text { expressivism } \\
\text { The doctrine of } \\
\text { dual effect }\end{array}$} & Abortion & $\begin{array}{l}\text { Closure of } \\
\text { knowledge }\end{array}$ \\
\hline & Functions & & Immigration & Minimalism and \\
\hline & $\begin{array}{l}\text { Mathematical structure } \\
\text { of quantum mechanics }\end{array}$ & & \multirow{3}{*}{$\begin{array}{l}\text { Moral status of } \\
\text { animals } \\
\text { Rape and } \\
\text { sexual violence }\end{array}$} & $\begin{array}{l}\text { The exclusion } \\
\text { problem }\end{array}$ \\
\hline & \multirow[t]{2}{*}{ Symmetry in physics } & & & Truthmakers \\
\hline & & & & $\begin{array}{l}\text { Zombies \& } \\
\text { conceivability } \\
\text { problem }\end{array}$ \\
\hline
\end{tabular}

\section{Data sources and data processing}

In the first step we downloaded the bibliographic records of all 8,097 items in the 17 selected topics from Philpapers in October 2019. From these we selected all 5,178 items published between 2000 and 2017, including 3,976 journal articles, 310 books, 677 chapters in collections, $72 \mathrm{PhD}$ theses and 143 unpublished works. We then matched these records to Web of Science

\footnotetext{
${ }^{6}$ https://philpapers.org/browse/all, accessed on 19, June, 2020.
} 
Core Collection (WoS) indexed papers to obtain their citation and reference data. With 2,373 articles out of 5,178 items indexed in both databases, the overall WoS coverage was $46 \%$. To ensure that the coverage of each topic was sufficiently high, we replaced three topics with low WoS coverage. ${ }^{7}$ In total, then, we collected 5,097 Philpapers items published between 2000 and 2017, and then performed bibliometric analysis on the 2,369 papers of these that are indexed in WoS. The whole process is illustrated in Figure 1. The numbers of papers and index ratio of each final topic are listed in Table 2.

\begin{tabular}{|c|c|c|}
\hline \multirow{4}{*}{$\begin{array}{l}\text { Downloaded all the } \\
\text { bibliographic records in } \\
\text { the } 17 \text { initially selected } \\
\text { topics from Philpapers } \\
\qquad \rightarrow 8,097 \text { items }\end{array}$} & $\begin{array}{l}\text { Selected items published } \\
\text { between } 2000 \text { and } 2017 \\
\quad \rightarrow 5,178 \text { items }\end{array}$ & $\begin{array}{c}\text { Matched these records } \\
\text { with WoS indexed papers } \\
\rightarrow 2,373 \text { articles }\end{array}$ \\
\hline & & \\
\hline & $\begin{array}{l}\text { Replaced three topics } \\
\text { with low WoS coverage }\end{array}$ & $\begin{array}{l}\text { Matched these records } \\
\text { with WoS indexed papers }\end{array}$ \\
\hline & $\rightarrow 5,097$ items & $\rightarrow 2,369$ articles \\
\hline
\end{tabular}

Figure 1. Data processes of sample selection

Table 2. Numbers of publications and indexed ratios of final 17 topics in three kinds of philosophy

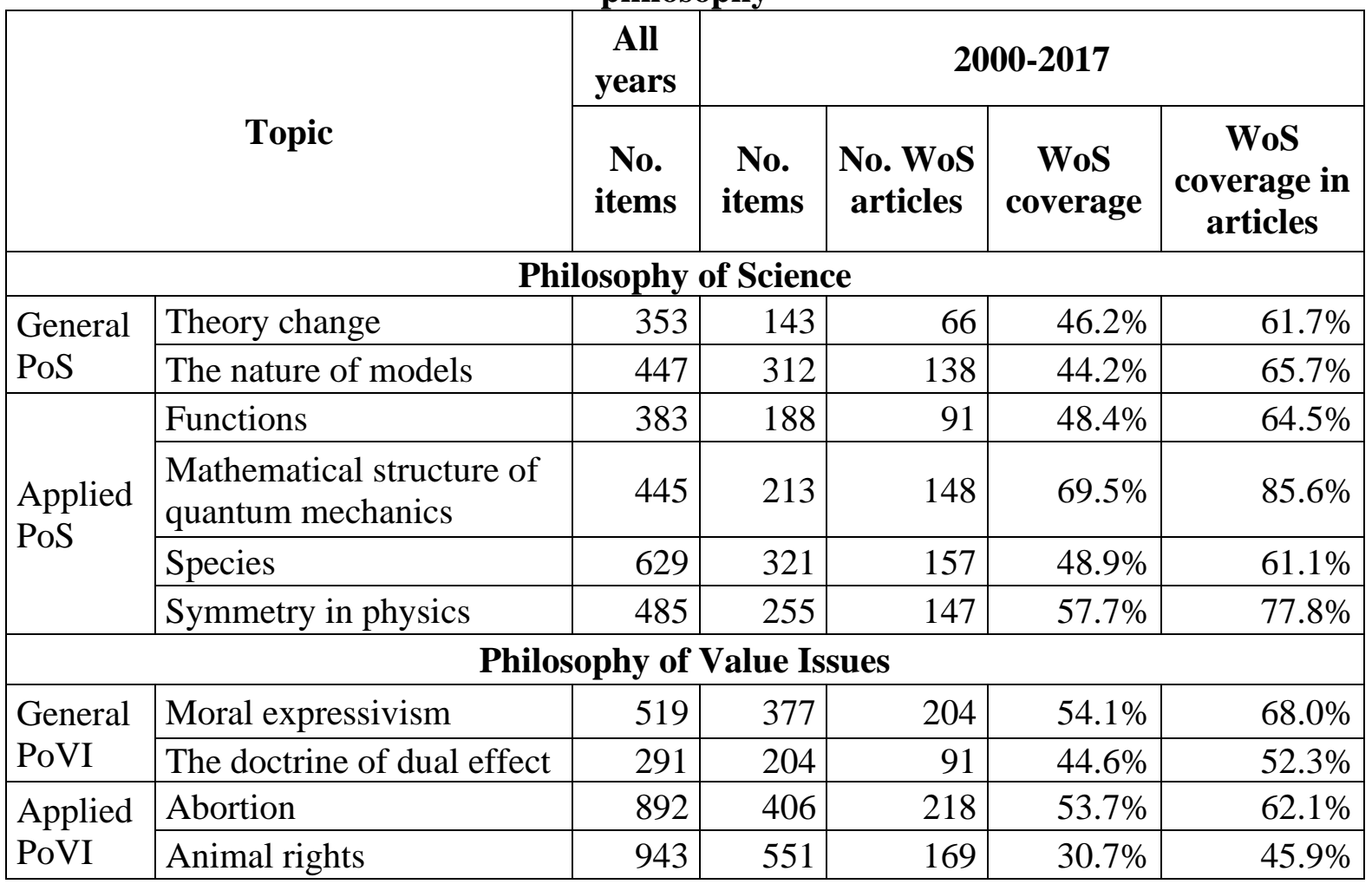

\footnotetext{
7 'Biodiversity' (42.2\%) was replaced by' Species' (48.9\%); 'Incommensurability in science' (32.5\%) was replaced by 'Theory change' (46.2\%); 'Immigration' (25.3\%) was replaced by 'Animal rights' (30.7\%). Because coverage was generally lower in topics from PoVI, not all topics selected from that field to replace topics with low coverage actually had higher coverage. In those cases, we kept the original topics.
} 


\begin{tabular}{|c|c|c|c|c|c|}
\hline Moral status of animals & 308 & 209 & 80 & $38.3 \%$ & $55.6 \%$ \\
\hline Rape and sexual violence & 427 & 280 & 85 & $30.4 \%$ & $37.1 \%$ \\
\hline \multicolumn{6}{|c|}{ Core Philosophy } \\
\hline Closure of knowledge & 241 & 171 & 92 & $53.8 \%$ & $65.7 \%$ \\
\hline $\begin{array}{l}\text { Minimalism and } \\
\text { deflationism }\end{array}$ & 590 & 399 & 164 & $41.1 \%$ & $59.9 \%$ \\
\hline The exclusion problem & 542 & 386 & 201 & $52.1 \%$ & $70.8 \%$ \\
\hline Truthmakers & 588 & 468 & 229 & $48.9 \%$ & $64.8 \%$ \\
\hline $\begin{array}{l}\text { Zombies \& conceivability } \\
\text { problem }\end{array}$ & 338 & 214 & 89 & $41.6 \%$ & $57.1 \%$ \\
\hline
\end{tabular}

The WoS matching algorithm used in this study was based on an algorithm developed by $\mathrm{ECOOM}^{8}$ and specifically modified for the field of philosophy. The algorithm applies regular expression and $\mathrm{N}$-grams matches to the downloaded bibliographic records and then uses the following five criteria to ensure the correctness of matches with WoS data: 1) identical unique identifier, i.e. DOI; or 2) identical source title, volume, issue and begin page; or 3) identical entire article title which is more than 30 characters, volume and source title; or 4) identical source title, volume, begin page and fuzzy title match starting from the $10^{\text {th }}$ character; or 5) identical publication year, volume, begin page, source title and fuzzy title match. The different variations of source titles were first checked and compared with the journal abbreviation database collected by ECOOM in previous projects. Only matches seen as identical to WoS indexed items were taken into account in this study.

The matched results suggest that the general WoS coverage in philosophy is around 40-50\% for the time-range of the study, which is higher than the coverage of around 30\% reported by local depositories for philosophy (cf., Butler \& Visser, 2006; Engels et al., 2012; Sivertsen \& Larsen, 2012). We speculate that the coverage in this study is higher because researchers may have been required to upload all of their publications to institutional/national depositories but might only upload their academic publications to Philpapers. In addition, we increased the coverage slightly by replacing three topics with low coverage. Finally, the higher coverage may also be due to the fact that WoS coverage of philosophical papers has increased since previous studies. This is reflected in Figure 2, which shows increasing yearly WoS coverage rates while the total number of publications remains stable. In this respect, the dataset of this study confirms a broader international trend in increasing WoS coverage across fields in the social sciences and humanities (see Engels et al., 2012; Chi, 2015).

The limited coverage of Philpapers documents in WoS forms a limitation of this study: in the end, only half of the publications from the comprehensive philosophy database - and only source items ${ }^{9}$ - were analysed. However, there is no bibliographic index that provides both a classification system maintained by experts and reference/citation data of indexed publications. As this study requires both, the most efficient solution was to use the Philpapers classification

\footnotetext{
${ }^{8}$ Over the course of 7 years, the ECOOM algorithm has automatically matched several hundred-thousands of references to WoS records with a $85 \%-90 \%$ rate of correct matching. The algorithm further suggests appropriate matches for the remaining 10-15\% of false negative matches, which were manually validated to be $70 \%$ correct. ${ }^{9}$ According to Butler and Visser (2006, p. 330), source items are "articles appearing in journals indexed by the Institute for Scientific Information (ISI) in one of its three main indexes - Science Citation Index (SCI), Social Sciences Citation Index (SSCI), and Arts and Humanities Citation Index (A\&HCI)."
} 
system and retrieve data of the targeted records through an authorised citation index. WoS was chosen because our team has abundant experience in matching and analysing data from it.

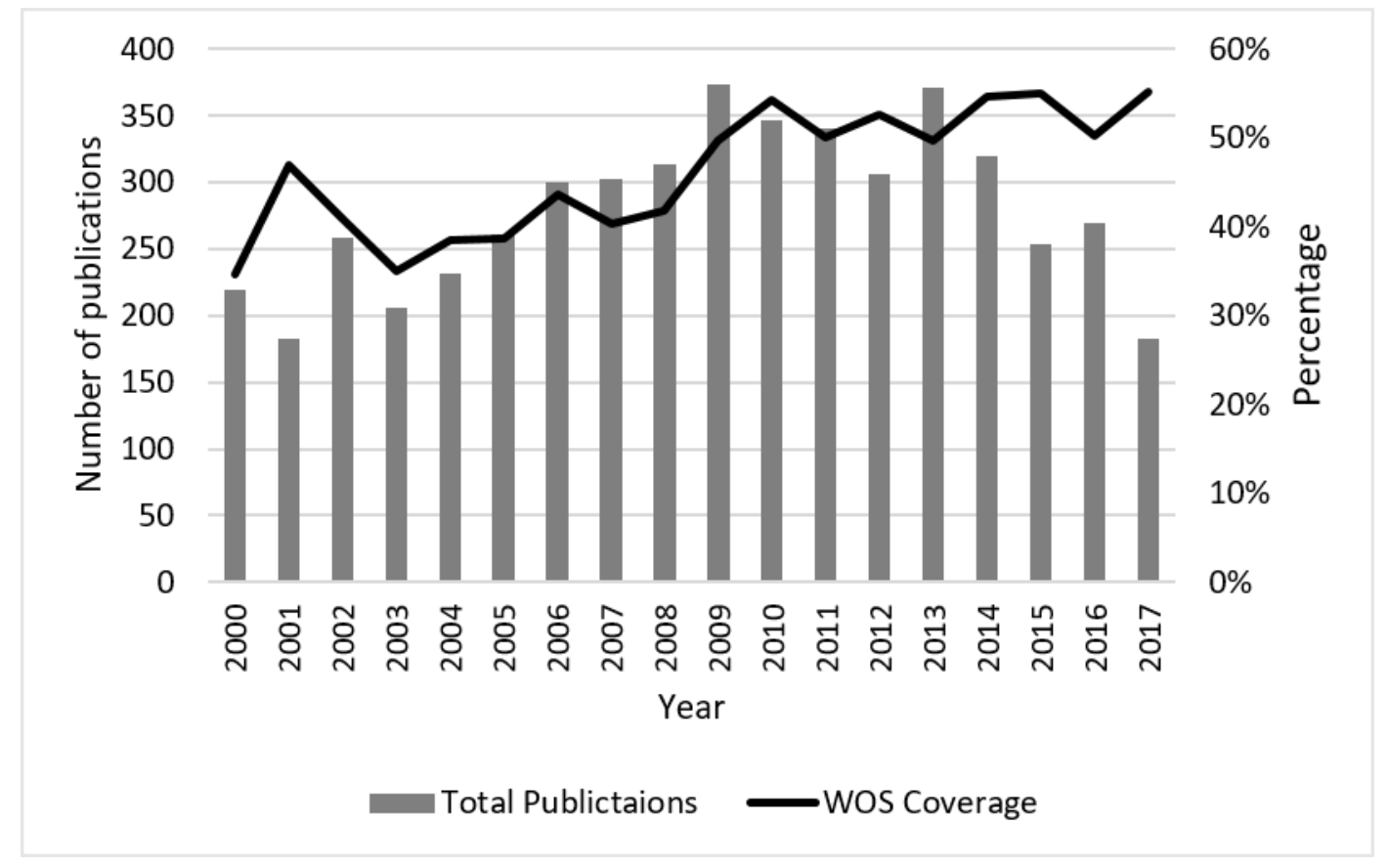

Figure 2. Yearly total number of publications and share of WoS publications of 17 selected topics in philosophy (2000-2017)

\section{Indicators}

'Isolation' is a vague term that can be understood in multiple distinct ways, even if we limit it to isolation from academic research (as opposed to, for example, isolation from society). First, the papers in a topic may be isolated with respect to the research they take into account, and they may be isolated with respect to the research they subsequently influence. In other words, there are two 'directions' of isolation: a lack of influence on other topics, and a lack of influence from other topics. Second, there are at least two relevant subsets of academic research from which a philosophical research topic may be isolated: a philosophical topic can be isolated from other topics within philosophy; and a philosophical research topic can be isolated from research topics in different fields. These different dimensions of isolation are logically independent: it is conceivable that a research topic has great impact in different academic fields, but does not build on work from those fields. Similarly, it is conceivable that a research topic is isolated from other fields, but not from other topics within philosophy. It follows that it may not be possible to measure academic isolation with a single indicator. Hence, this section introduces multiple indicators to track different dimensions of isolation.

Since research topics can be isolated both from other parts of philosophy and from other academic fields, we have to define two borders within academic publishing: a bigger one that confines the whole field of philosophy; and a smaller one that encloses the selected topics within philosophy. We defined the former border by means of three philosophy-related WoS subject categories: History \& Philosophy of Science, Philosophy, and Ethics. Topic-borders were defined by the 17 Philpapers topics as listed in Table 2. These two borders provide us with three levels of isolation, as illustrated by Figure 3: Isolation of a topic from academic 
research in general (General isolation), isolation from other academic fields (Disciplinary isolation), and isolation of a topic from other topics within philosophy (Isolation from philosophy).
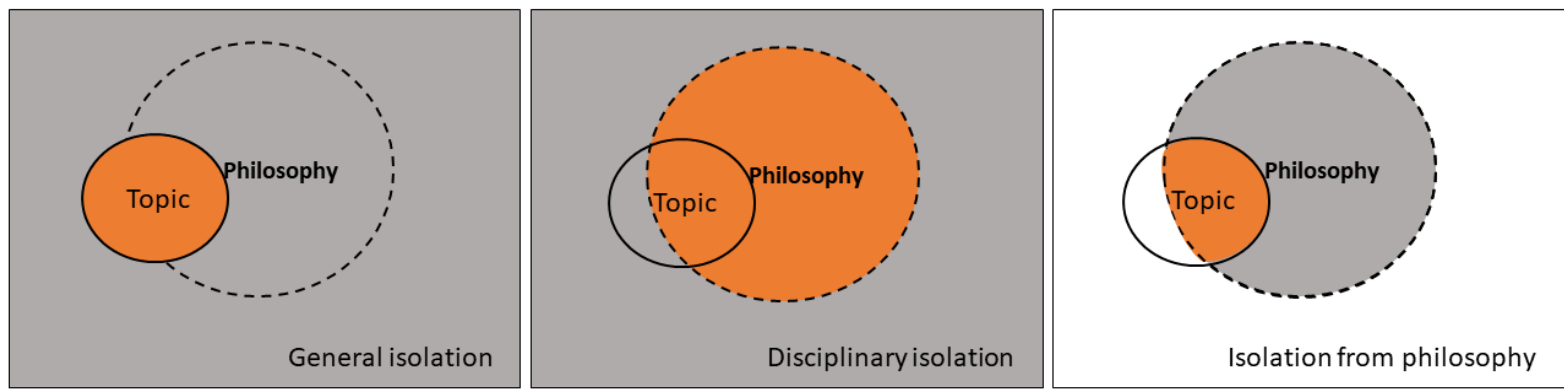

Figure 3. Three levels of isolation of kinds of philosophy. A. General isolation B. Disciplinary isolation C. Isolation from philosophy. The indicators measure the extent to which topics are isolated from the grey area. In each of the levels, the citation-based and reference-based indicators measure isolation as the proportion of a topic's citations and references coming from the orange area (where the total number is represented as the grey+orange area). The impact indicators show the average number of citations per paper coming from the grey area.

To ensure that we track isolation as a lack of influence both on and from other topics, we apply three kinds of indicators in each of these three levels (see figure 3 for a visualisation of these indicators):

1) The citation-based indicators track the isolation of the topics by measuring what proportion of a topic's citations comes from inside the topic. Thus, these indicators track isolation as a topic's lack of influence on other topics. Implementing this for each of the three levels, Citgen is the proportion of a topic's citations that come from within the topic; Cit $_{\text {disc }}$ is the proportion of a topic's citations that come from philosophy; and Cit $t_{\text {phil }}$ is the proportion of a topic's philosophical citations that come from inside the topic.

2) The reference-based indicators track the isolation of the topics by measuring what proportion of a topic's references are to papers in the topic. Thus, these indicators track isolation as lack of influence from other topics. Implementing this for each of the three levels, $R e f_{g e n}$ is the proportion of a topic's references that are from the same topic; $R e f_{d i s c}$ is the proportion of a topic's references that are from philosophy; and Ref $f_{\text {phil }}$ is the proportion of a topic's philosophical references that are from the same topic.

3) The impact indicators measure the average citation impact of a topic on work outside the topic. Thus, the lower a topic scores for these indicators, the more isolated it is. These impact indicators are also useful to qualify the citation-based indicators. Because the latter track proportions, they may indicate that a topic is not very isolated even if there are very few citations from outside the topic (namely, when there are very few citations in general). Thus, the citation-based indicators should be interpreted in combination with the impact indicators. Implementing the impact indicators for each of the three levels, Imp gen shows how often on average each paper in the topic is cited by papers from outside the topic; Imp $p_{\text {disc }}$ shows how often on average each paper in the topic is cited by papers 
from outside the field; and Imp phil shows how often on average each paper in the topic is cited by philosophical papers from outside the topic.

These 9 indicators ( 3 for each of the three levels of isolation, see figure 3 ) all measure isolation through citations and references. To avoid that our investigation of isolation in philosophy is entirely dependent on these indirect connections, we also take into account the relatively direct and subjective links of collaboration. Unlike in most other fields of research, philosophical papers are typically single-authored. This reflects 'the popular image of [...] philosophers [...] as independent scholars, working, or at least writing, in relative isolation' (Cronin et al 2003, p. 868). Writing papers in collaboration with others breaks such isolation in the minimal sense that at least two points of view, and often also two research specializations or academic disciplines, are combined.

To measure isolation through collaboration practices, we determined for each multi-authored paper whether it was a collaboration between philosophers, between non-philosophers, or between at least one philosopher and at least one non-philosopher. To do this, we relied on author affiliations provided by WoS to determine whether the authors of a paper are philosophers (affiliated to a philosophy department) or non-philosophers (not affiliated to a philosophy department). It goes without saying that in reality the distinction between philosophers and non-philosophers are sometimes vague, and one researcher can plausibly fit in both categories; however, we ignore these complications for the purposes of this study and assume that researchers are either philosopher or non-philosopher, and that this is reliably indicated by their affiliation.

After excluding 10 papers without address data, we applied multiple criteria to the 379 multiauthored papers from the 17 topics (authored by 971 individual authors) ${ }^{10}$ in two groups: papers showing clear correspondence between addresses and authors, and papers without correspondence between addresses and authors. The lack of correspondence between addresses and authors was not due to WoS, but mainly to publication patterns adopted by authors and journals. For the first group we deduced the authors' field from their corresponding addresses in 5 steps (see Appendix B).

The same steps were also applied to each address in the second group. Even though we cannot identify philosophers for the papers in this group due to the lack of individual author affiliations, the field of addresses (philosophy or non-philosophy) of a paper plus the number of its authors provides enough proof to detect whether the paper is a collaboration between someone with a philosophical affiliation and someone with a non-philosophical affiliation. In total, we found that 174 papers were collaborations by only philosophers, 139 papers were published by only non-philosophers, and 66 papers were collaborations by at least one philosopher and one non-philosopher. We used these data for a final set of indicators:

4) The Collaboration-based indicators measure isolation as the degree to which papers in a topic are written in collaboration between multiple authors. More precisely, Col $_{\sin }$ tracks the proportion of papers in a topic that are single-authored; and Col $_{\text {disc }}$ tracks the proportion of papers in a topic that are a collaboration between philosophers and non-

\footnotetext{
${ }^{10}$ The average number of authors per paper is 2.5857 . The topic 'Rape and sexual violence' has the highest number of authors, namely, 3.2621.
} 
philosophers. This latter indicator is particularly relevant because it signals how often philosophers working on a topic directly engage with researchers from other fields.

All in all, then, this study relies on 11 indicators divided into four categories: General isolation $\left(C_{i t_{g e n}}, \operatorname{Ref}_{\text {gen }}, \operatorname{Imp}_{\text {gen }}\right)$, Disciplinary isolation $\left(\operatorname{Cit}_{d i s c}, \operatorname{Ref}_{\text {disc }}, \mathrm{I} \mathrm{Pp}_{\text {disc }}\right)$, Isolation from Philosophy $\left(\right.$ Cit $_{\text {phil }}, R e f_{\text {phil }}$, Imp phil $_{\text {p }}$, and Collaborative isolation $\left(\operatorname{Col}_{s i n}, \mathrm{Col}_{\text {disc }}\right)$. Detailed discussions and definitions of each indicator are listed in Appendix C.

The data needed to calculate these indicators were extracted in March 2020 from the ECOOM in-house database with WoS raw data. Self-citations were not excluded as self-citing is seen as natural citing behavior and its effect is not expected to obstruct this study significantly. For the reference-based indicators, only source references indexed in WoS were counted as it was not possible to identify the philpapers-topic and WoS-field of non-source references. ${ }^{11}$ Similarly, only WoS indexed documents were included for calculating the other indicators. Hence, whenever we refer to a 'topic' below, this should be understood as 'those papers from the topic that are indexed in WoS'.

\section{Results}

\section{Isolation and citation impact}

The results of all indicators for all topics are listed in Appendix D. Table 3 shows the aggregated values of all indicators for the three kinds of philosophy. Figure 4 presents these indicators for the three kinds of philosophy as well as their citation impact from Table 3 . The detailed charts of its sub-charts for the three levels of isolation can be found in Appendix E. The differences between the three kinds of philosophy are clearly significant. Topics in PoS are the least isolated in terms of impact, who cites them, and the works they cite. Topics in PoVI are in general slightly more isolated than those in PoS, and topics in CP are more isolated than those in PoS and PoVI across nearly all indicators.

\footnotetext{
${ }^{11} \mathrm{WoS}$ coverage of references is around $25.8 \%$ for the 17 topics. The topic 'Functions' has the highest share of WoS indexed references (37\%,) while the topic 'Rape and sexual violence' has the lowest ratio (17.9\%). Among the three kinds of philosophy, 'Philosophy of Science' has highest ratio of indexed references $(28.6 \%)$, followed by 'Core Philosophy' (26.3\%) and 'Philosophy of Value Issues' (21.5\%).
} 


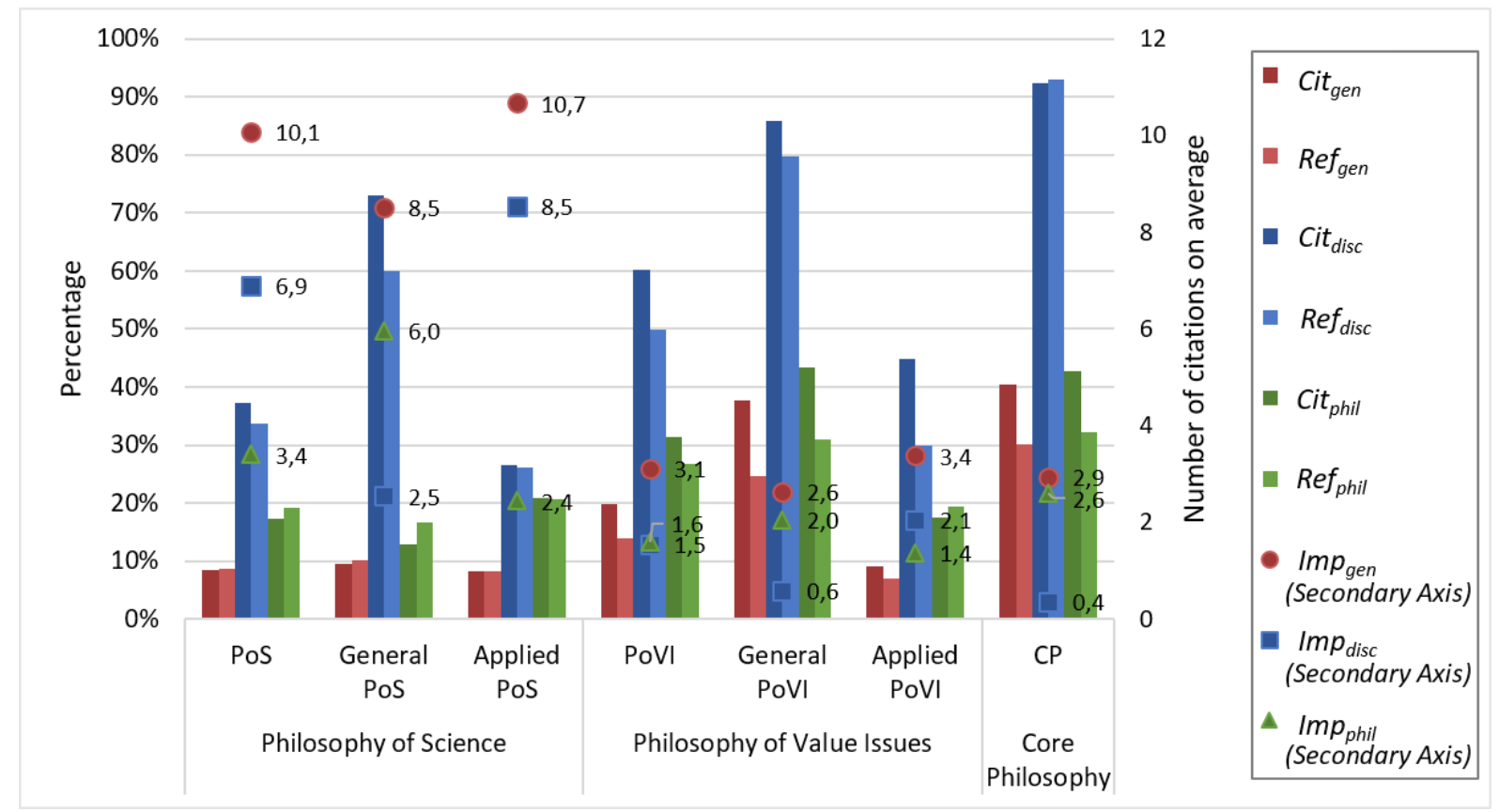

Figure 4. Citation and reference related indicators and citation impact of 17 topics in three kinds of philosophy (2000-2017)

However, Figure 4 also shows that general PoVI topics show similar citation patterns as CP. Indeed, there were significant differences within PoS and PoVI between general topics (i.e. closer to $\mathrm{CP}$ ) and applied topics (i.e. further from $\mathrm{CP}$ ). In both PoS and PoVI, the general topics were substantially more isolated from other academic fields (see Appendix E-2) than the applied topics. For PoVI, the general topics were also more isolated from academic research in general (see Appendix E-1) and within philosophy (see Appendix E-3) than the applied topics.

Taking a closer look at the three levels of isolation shown in Figure 5, it is clear that the differences between the three kinds of philosophy are similar across indicators and levels of isolation. In terms of the difference of General isolation and Disciplinary isolation, PoS has larger disparity than the other two kinds of philosophy, revealing that its topics are less part of philosophy and so have fewer citations (or references) from papers that are part of philosophy or the topic. For $\mathrm{CP}$, the difference between these two levels of isolation is much smaller. Furthermore, indicators for CP differ the least between General isolation and Isolation from Philosophy. All this implies that CP mostly cites, and is cited by, papers from philosophy. This also confirms CP's high values for indicators Cit $_{\text {disc }}$ and Ref $_{\text {disc }}$ in Disciplinary isolation, and the large gap between these indicators for CP on the one hand, and PoS and PoVI on the other. 


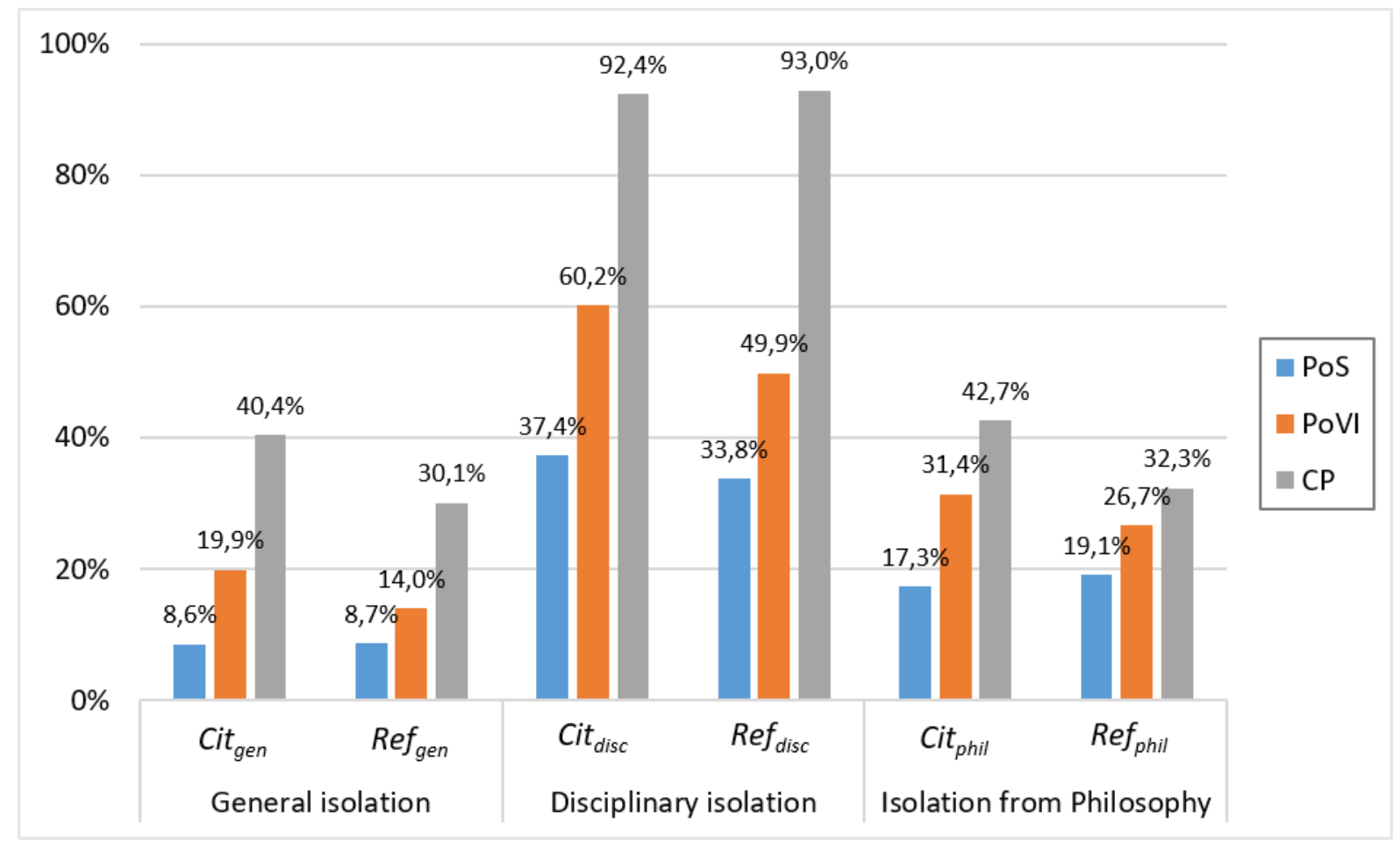

Figure 5. Citation and reference related isolation indicators of three kinds of philosophy at three levels of isolation (2000-2017) 
Tabel 3. Aggregated values of all isolation indicators for the three kinds of philosophy (2000-2017)

\begin{tabular}{|c|c|c|c|c|c|c|c|c|c|c|c|}
\hline & \multicolumn{3}{|c|}{ General isolation } & \multicolumn{3}{|c|}{ Disciplinary isolation } & \multicolumn{3}{|c|}{ Isolation from Philosophy } & \multicolumn{2}{|c|}{ Collaborative isolation } \\
\hline TOPIC & Cit $_{\text {gen }}$ & Ref $f_{\text {gen }}$ & Imp $_{\text {gen }}$ & Cit disc $_{\text {. }}$ & $\operatorname{Ref}_{\text {disc }}$ & Imp $_{\text {disc }}$ & Cit $_{\text {phil }}$ & Ref $f_{\text {phil }}$ & Imp phil & $\mathrm{Col}_{\sin }$ & Col $_{\text {disc }}$ \\
\hline Philosophy of Science & $8.6 \%$ & $8.7 \%$ & 10.1 & $37.4 \%$ & $33.8 \%$ & 6.9 & $17.3 \%$ & $19.1 \%$ & 3.4 & $75.8 \%$ & $4.3 \%$ \\
\hline General PoS & $9.6 \%$ & $10.2 \%$ & 8.5 & $72.9 \%$ & $59.9 \%$ & 2.5 & $12.9 \%$ & $16.7 \%$ & 6.0 & $83.3 \%$ & $3.9 \%$ \\
\hline Applied PoS & $8.3 \%$ & $8.2 \%$ & 10.7 & $26.6 \%$ & $26.1 \%$ & 8.5 & $20.9 \%$ & $20.7 \%$ & 2.4 & $72.9 \%$ & $4.4 \%$ \\
\hline Philosophy of Value Issues & $19.9 \%$ & $14.0 \%$ & 3.1 & $60.2 \%$ & $49.9 \%$ & 1.5 & $31.4 \%$ & $26.7 \%$ & 1.6 & $85.7 \%$ & $3.7 \%$ \\
\hline General PoVI & $37.7 \%$ & $24.7 \%$ & 2.6 & $85.8 \%$ & $79.7 \%$ & 0.6 & $43.4 \%$ & $30.9 \%$ & 2.0 & $91.5 \%$ & $1.4 \%$ \\
\hline Applied PoVI & $9.1 \%$ & $6.9 \%$ & 3.4 & $44.7 \%$ & $30.0 \%$ & 2.1 & $17.4 \%$ & $19.4 \%$ & 1.4 & $82.6 \%$ & $4.9 \%$ \\
\hline Core Philosophy & $40.4 \%$ & $30.1 \%$ & 2.9 & $92.4 \%$ & $93.0 \%$ & 0.4 & $42.7 \%$ & $32.3 \%$ & 2.6 & $90.1 \%$ & $0.4 \%$ \\
\hline
\end{tabular}


In terms of overall citation impact, papers in PoS are generally cited the most, followed by those in CP and PoVI. Papers in the topics of PoS were cited 11 times on average; papers in PoVI and CP were on average cited 3.9 and 4.9 times respectively. Figure 6 compares the overall average citation rates (Mean Citation Rates, MCRs) and the impact indicators - impact outside the topic, outside the field, and outside the topic but within philosophy - of the three kinds of philosophy. It is not suprising that PoS received most citations, especially from outside philosophy, as it is closest to the natural sciences. The indicator Citgen $_{\text {in Figures }} 4$ and 5 prove that most citations of papers in PoS are indeed from outside the topic. Because of this, their Imp gen values are close to their average citation rates, and their Imp phil values are much higher than the other categories. The only exception here is the topic 'Theory change' which has much lower average citation rate (4.0), Imp gen and Imp phil than other PoS topics (see Appendix D). The low Imp disc of $\mathrm{CP}$, compared to its $M C R$, indicates that topics in $\mathrm{CP}$ received very few citations from papers outside philosophy. This confirms their Disciplinary isolation as indicated by the citation-based and reference-based indicators discussed above. Figure 6 also shows clearly that the impact outside philosophy $\left(\operatorname{Imp}_{\text {disc }}\right)$ is much lower for general PoS and PoVI topics than for applied topics. This confirms the high rates of citations and references from outside philosophy that these applied topics have (see Appendix E-2) and shows that general topics are relatively closer to $\mathrm{CP}$.

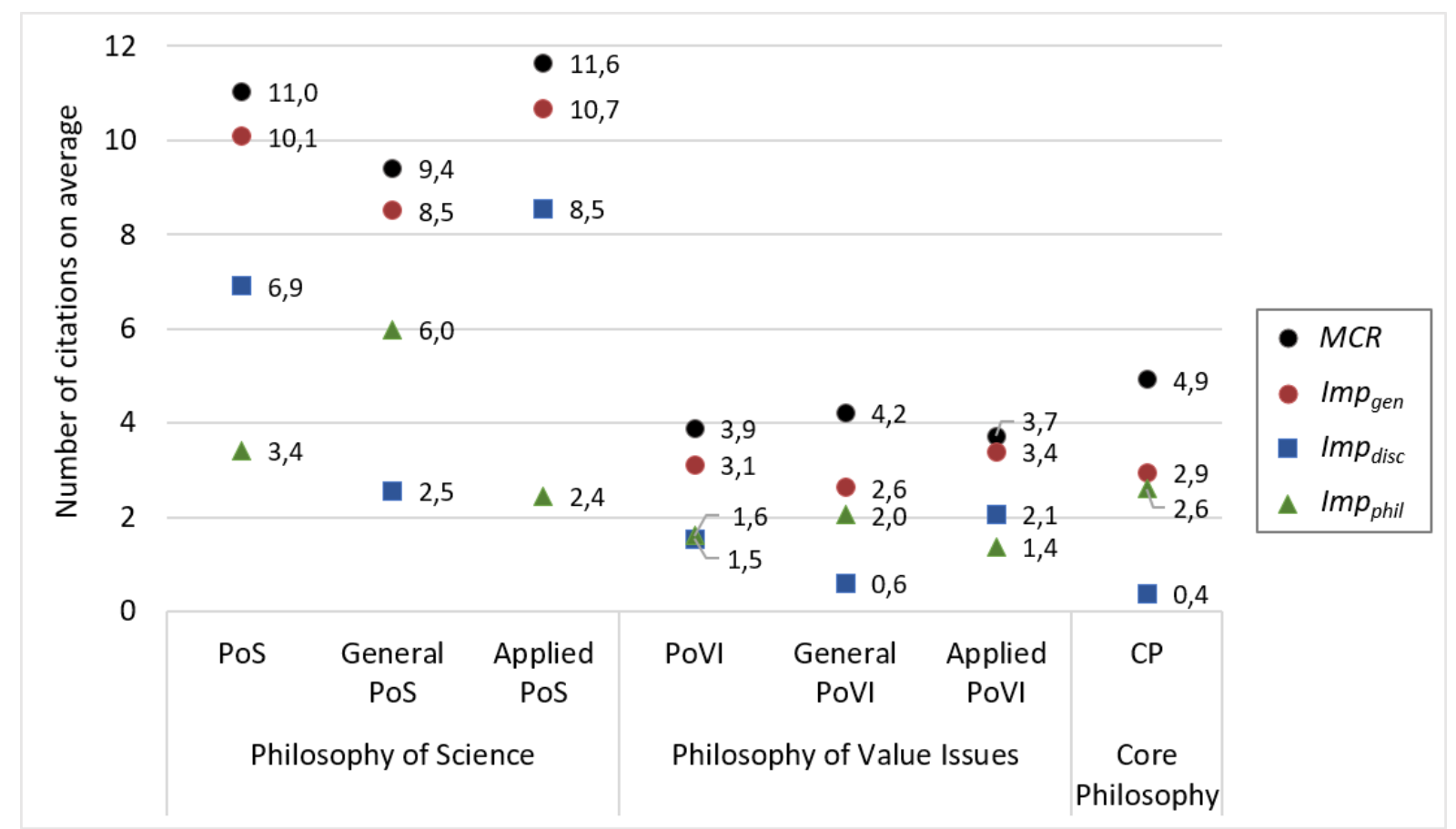

Figure 6. Citation impact indicators of the three kinds of philosophy (2000-2017)

\section{Isolation and co-authorship}

The average number of authors per co-authored paper in the 17 philosophical topics is 2.56 , but the average number of authors per paper in the data set is only 1.25. This low number is in line with the results of Cronin et al. (2003), who point out that philosophers acknowledge and co-author less than researchers in other disciplines. Figure 7 shows that the rate of singleauthored papers is generally high, and particularly high in CP where $90 \%$ of all papers are single-authored. Moreover, $92 \%$ of the few multi-authored papers are collaborations of only 
philosophers according to their affiliations (see Figure 8). In CP, collaborations between philosophers and non-philosophers even constitute less than $1 \%$ of all the papers in the category

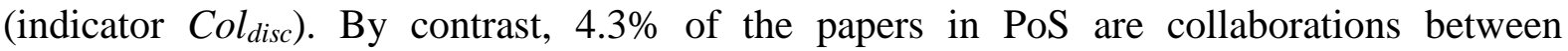
philosophers and non-philosophers. Among the multi-authored publications in PoS (24\% of the total publications), 70\% have non-philosophers among their authors (see Figure 8). Figure 8 also shows that papers from PoVI were even more often authored by a collaboration of philosophers and non-philosophers among the co-authored works than papers in PoS.

Interestingly, we found that philpaper topics in PoS and PoVI often have many papers written by authors with only non-philosophical affiliations, such as biologists, physicists, sociologists and psychologists. These collaborations without philosophers were often published in nonphilosophical journals. This is particularly the case for papers in philosophy of physics. Nearly half of the papers in PoS written by only non-philosophers were published in journals belonging to the WoS subject category "PHYSICS, MULTIDISCIPLINARY" and overall twothirds of these papers were from physics.

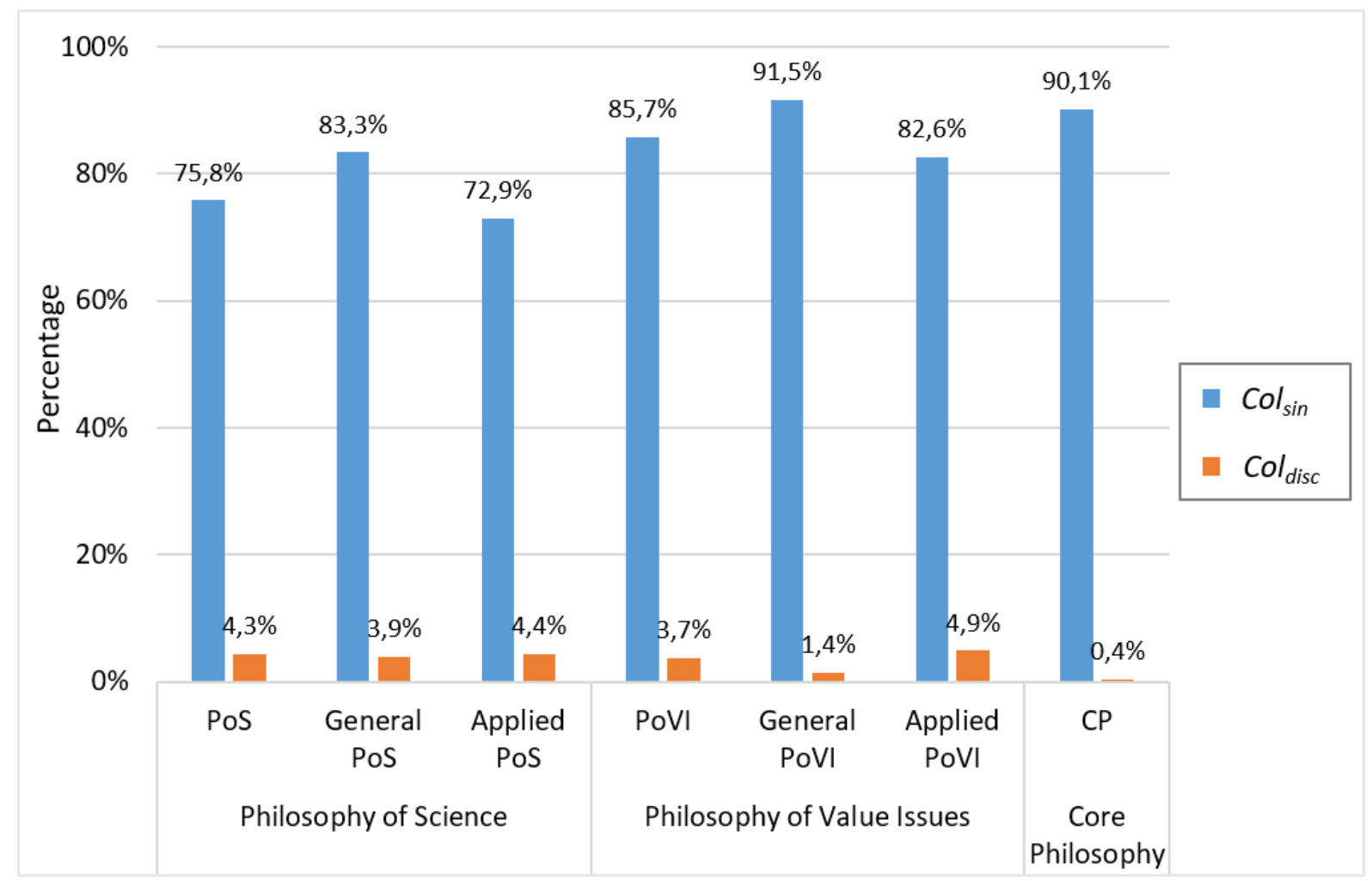

Figure 7. Collaboration isolation indicators of the 17 topics in three kinds of philosophy (2000-2017) 


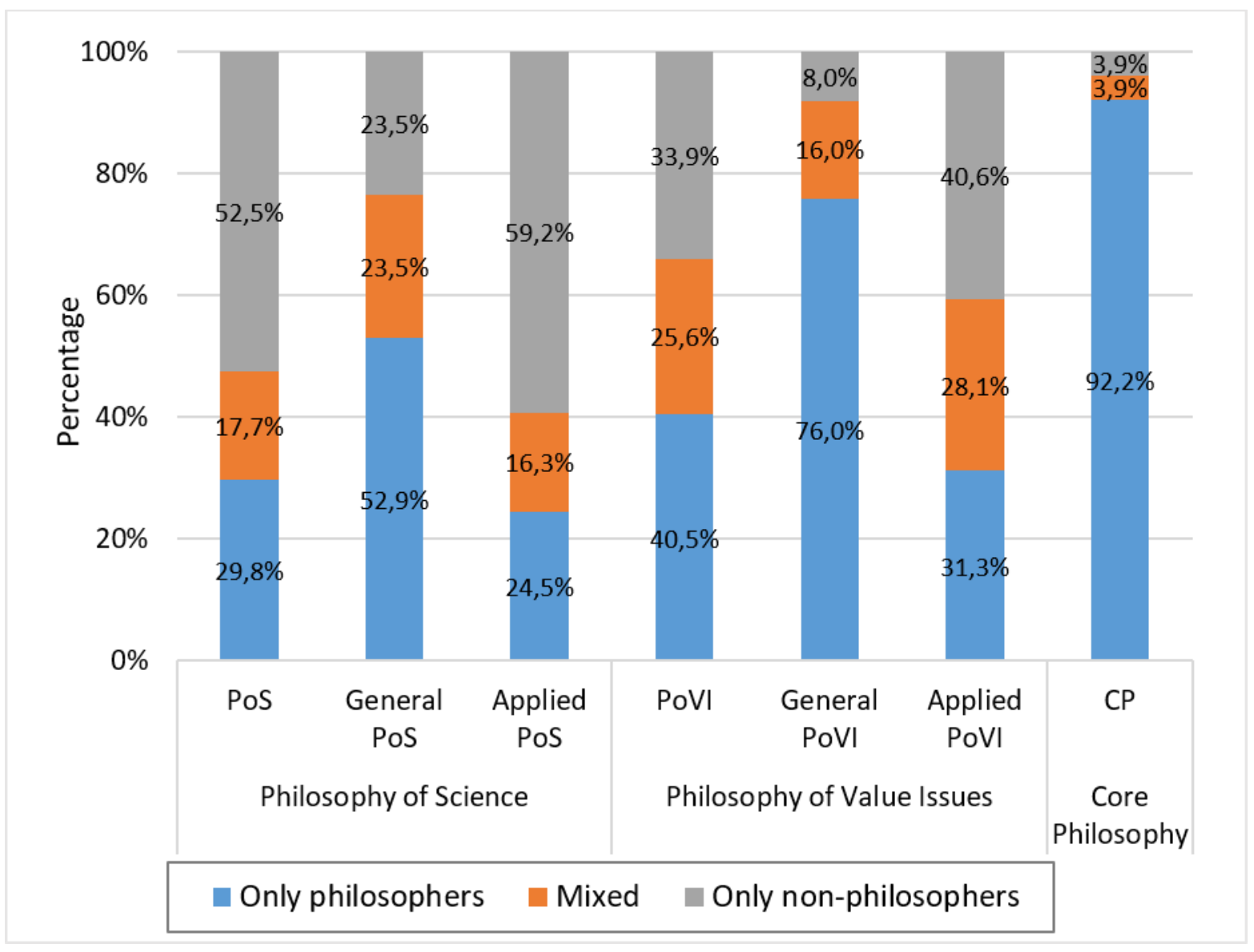

Figure 8. Shares of three types of collaboration among multi-authored papers of the three kinds of philosophy (2000-2017)

\section{Discussion and Conclusions}

The three hypotheses, drawn from the philosophical literature, were all confirmed by the indicators for isolation used in this paper. However, nuance is important here, as they were confirmed to different degrees, and not always for all different dimensions of isolation.

Hypothesis $\mathrm{A}$ - that PoS is less isolated than $\mathrm{CP}$ - was confirmed across nearly all indicators: in academic research in general, within philosophy, from other academic fields, and with respect to collaboration-practices. Particularly the difference in isolation from other academic fields shows very strongly. Over $90 \%$ of the citations and references for CP topics come from philosophy, compared to less than $40 \%$ for PoS. In this respect, this study confirms the findings of McLevey et al. (2018). Particularly noteworthy also is the relatively high degree of multiauthored papers that philosophers of science write. This confirms the results of survey-research by Plaisence et al (2019), in which nearly all philosophers of science reported to have coauthored work with philosophers and well over half with scientists.

Hypothesis B - that PoVI is less isolated than CP - was also confirmed, but less strongly than hypothesis A. The relatively high proportion of citations and references from outside the topics suggest that PoVI is less isolated from academic research in general, from the rest of philosophy, and, most strongly, from other academic fields. Similarly, topics from PoVI tend to have more papers that are collaborations between philosophers and non-philosophers. 
Interestingly, this pattern is not confirmed by the impact indicators, which shows that the impact of PoVI topics on other research is similar to that of CP topics, and clearly lower than topics in PoS. This inconsistency between this impact-indicator and other indicators may be explained by differences in citation practices across disciplines. Specifically, $95 \%$ of papers in CP were published in the field Arts \& Humanities according to the modified Leuven-Budapest classification system assorting 16 major fields and 74 subfields based on all the ISI subject categories (see Glänzel et al. 2016); however, only $60 \%$ of PoVI papers and $56 \%$ of PoS papers were published in Arts \& Humanities. Another 24\% of PoVI papers were published in the field Social Sciences I and additional $28 \%$ of PoS papers are in Physics. It is generally expected that papers in the social sciences would receive less citations than papers in physics ${ }^{12}$ due to different citation practices and insufficient database coverage (see Hicks 1999; Nederhof 2006; Chi 2014). Unsurprisingly, then, PoVI and CP are cited less often, and have higher uncited rates (32\% and $31 \%$ respectively) than $\operatorname{PoS}(20 \%)$.

Given these differences in citation practices between fields, one could argue that the results for hypotheses A and B may be due to the fact that topics in PoVI and PoS have a substantial proportion of papers that are authored by non-philosophers and published in non-philosophical journals. However, this does not explain the consistently large gaps between PoS/PoVI and CP across most indicators. Moreover, even if there are disciplinary differences with respect to citation practices, it remains plausible that philosophical papers with more citations outside of philosophy are more influential outside of philosophy. The crux of the issue lies in the question of whether papers from non-philosophical journals and with non-philosophical authors can be considered part of the philosophical topics. We argue that the answer is clearly affirmative. Philpapers states explicitly that it aims to index just papers that are part of academic philosophy, but that these need not be published in philosophical outlets. As all philpaperstopics in this study are actively curated by a philosophical expert, this means that these papers were considered part of philosophical debates by a philosophical expert. Thus, the higher proportion in PoS and PoVI of papers authored by authors without a philosophical affiliation simply shows that these topics are more closely integrated with other fields of science.

Hypothesis $\mathrm{C}$ - that general topics in PoS and PoVI are more isolated than applied topics - was partially confirmed. More precisely, the hypothesis was confirmed for PoVI across all indicators. Again, this pattern was strongest for the indicators relating to isolation from other academic fields. For PoS, on the other hand, this hypothesis was confirmed for all indicators except for those relating to isolation within philosophy. This suggests that these general topics may be closer to $\mathrm{CP}$ than to their respective categories. Interestingly, it also suggests that general work in PoS tends to be less isolated within philosophy than general work in the other kinds of philosophy. One explanation for the difference between PoS and PoVI in this respect is that the fields of normative ethics and particularly meta-ethics, from which the topics for general PoVI were chosen, are traditionally more part of CP than general PoS. A more general explanation for the less isolated status of general PoS may be that papers in this area are more often multi-authored than those in general PoVI and CP. This suggests that encouraging collaborations may be one effective way of decreasing isolation of $\mathrm{CP}$ and general topics in the peripheral areas.

\footnotetext{
${ }^{12}$ For example, the 2020 ESI Field Baselines published by Clarivate reports that during the period 2010 to 2020 WoS papers in Social Sciences, General were cited 7.82 times on average while the papers in Physics were cited 11.9 times on average. https://esi.clarivate.com/, accessed on 9, October, 2020.
} 
Of course, these results should not be taken to imply that all $\mathrm{CP}$ is more isolated than all PoS and PoVI. Indeed, even within the most isolated topics used in this study there surely are publications that productively engage with work from other fields and topics. In addition, many philosophers from all three areas of philosophy are aware of the problems we discuss here, and actively look for solutions like 'field philosophy' (Brister and Frodeman 2020) or socially engaged philosophy of science (Cartieri and Potochnik, 2014; Fehr and Plaisance, 2010). Nevertheless, our results suggest that on a more general level, CP tends to be more isolated than PoS and PoVI. ${ }^{13}$

These results have at least three important implications for addressing the problem of isolation in philosophy. First, and most importantly, these results support Kitcher's (2011) claim that one way of decreasing the isolation of philosophical research would be to turn philosophy 'inside out': while currently CP dominates over the peripheral areas of philosophy (PoS and PoVI) in terms of prestige, funding, and teaching, these results suggest that isolation could be diminished by reversing this relation. Second, and related to this, these results suggest that such a reversal should prioritize in particular applied rather than general topics in Philosophy of Science and Philosophy of Value Issues.

Third, the results in this paper show that $\mathrm{CP}$, and to a smaller extent general topics in the peripheral areas, are particularly isolated from other fields of academia. This means that interventions that focus on this dimension of isolation are likely to have the largest impact. However, such interventions are most likely also very difficult, as they require a substantial change in the current academic culture of philosophy. As McLevey et al. (2018) show, receiving citations from outside philosophy has no impact on the academic success of philosophers of science. Assuming that time spent on publications aimed at other fields takes time away from more narrowly philosophical publications, this means that philosophers are currently punished for connecting to other fields of academia. And while philosophers of science broadly state that engaged or interdisciplinary work should be encouraged, a survey question asking if publications outside philosophy should be given equal weight received relatively low support (Tiberius 2017). Hence, there may be a gap between what philosophers say about engaging with other fields, and how they act when hiring or training students (see also Plaisence et al. 2019).

Finally, it is worth briefly discussing the limitations of this study. First, we have already pointed at the low WoS coverage of topic papers and references, and, more particularly, a bias towards source references over references to books and book chapters. This limitation is particularly worrying because it may be that philosophers in CP cite fewer source items (typically journal papers) and more other types of documents such as books. To ensure that journal papers are also commonly cited in $\mathrm{CP}$, we conducted a small test to estimate the composition of reference lists in CP papers. Figure 9 shows that even though journal papers are not the only type of references, they are clearly more common than books. In addition, the distribution of these references between philosophy and non-philosophy is clearly in line with our results based on

\footnotetext{
${ }^{13}$ It is also important to keep in mind that the isolation of philosophical research says nothing about the technical quality of the research. That is, these results should not be taken to imply that philosophical research from PoS and PoVI is superior in terms of analysis, reasoning or argumentation. Instead, PoS and PoVI show to be superior in terms of their relevance for other academic research.
} 
source references. This suggests that the low coverage and limitation to source items in the reference analysis of this study did not bias the results.

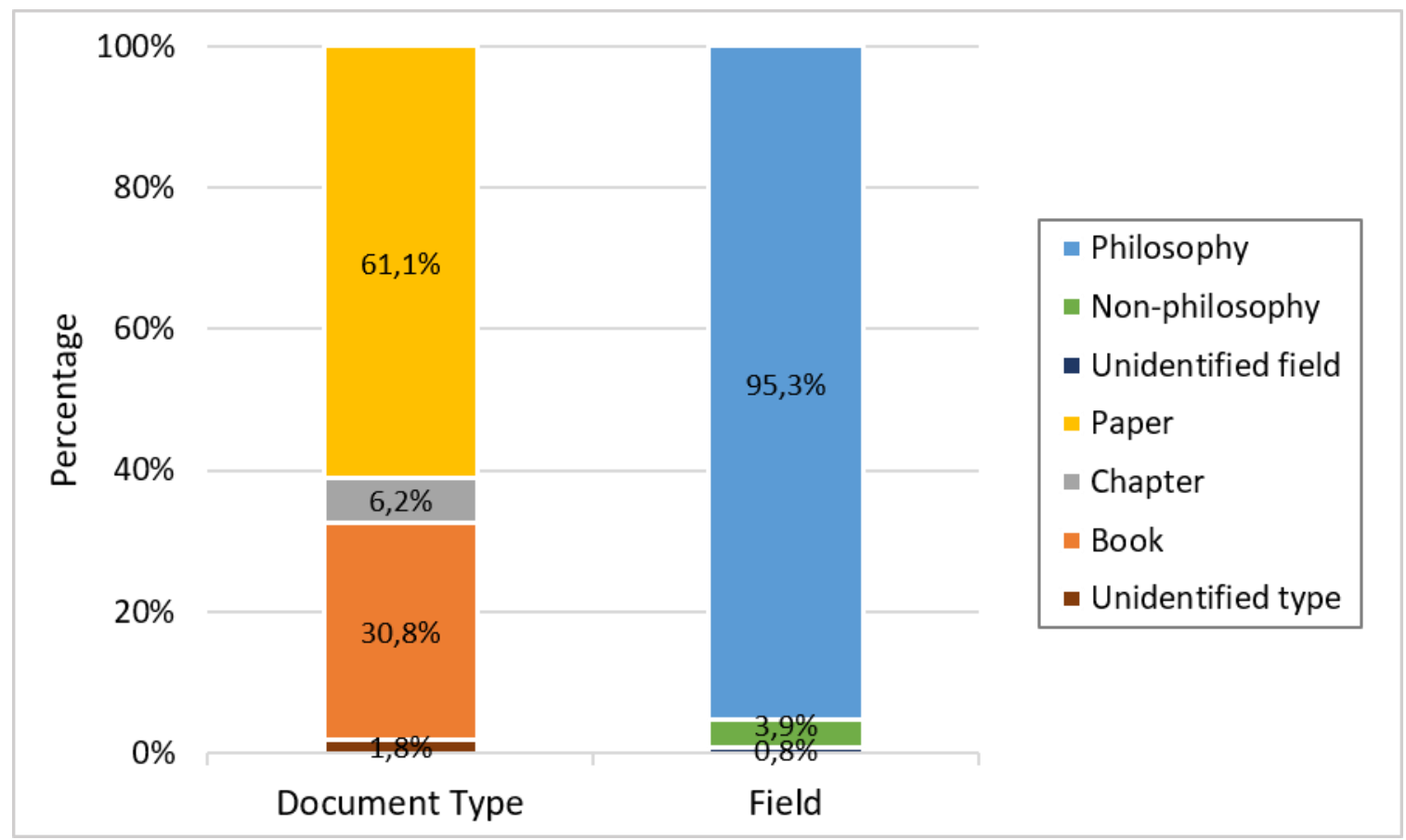

Figure 9. Reference composition of document type and field of 20 papers in $\mathbf{C P}$ Note: 20 papers were selected as those with median reference numbers in the 20 intervals formed by the 5 CP topics and 4 time periods (2000-2004, 2005-2008, 2009-2013, 20142017), containing 386 references. The second author checked these references manually.

A second limitation is that this study only measures direct academic influence and isolation through publications. As Plaisence et al. (2019) show, philosophers of science engage and collaborate with scientists in more ways than just co-authoring and citing papers. Our research does not capture such flows of influence. In addition, it may be that $\mathrm{CP}$ and general topics in the peripheral areas have indirect impact on work from other academic fields through the applied topics in the peripheral areas. For example, it may be that applied papers use ideas from $\mathrm{CP}$, which in turn influence work in other academic fields. Such indirect influence cannot be traced by the indicators here, but still alleviates the isolation of $\mathrm{CP}$ and general topics from the peripheral areas. However, such indirect influence is likely to be limited, as the indicators for influence within philosophy also show that applied topics are less isolated than $\mathrm{CP}$ and general topics.

Finally, this study only measures isolation with respect to academic research. It may well be that topics that are highly isolated in an academic sense are highly connected to other audiences, such as lay people and policy makers. This may be particularly so for topics in PoVI. While the results in this study suggest that topics in PoVI are more isolated than PoS-topics, it seems likely that they are less isolated from society. Hence, a complete picture of isolation of philosophy requires that such societal connections are also measured. We will take this up in a follow-up study to this paper.

\section{References}


Boghossian P, Lindsay J. Chmess, abiding significance, and rabbit holes. In: Blackford R, Broderick D, editors. Philosophy's Future: The Problem of Philosophical Progress. John Wiley \& Sons; 2017. p. 63-74.

Brister, E., \& Frodeman, R. (2020). A Guide to Field Philosophy: Case Studies and Practical Strategies. Routledge.

Butler, L., \& Visser, M.S. (2006). Extending citation analysis to non-source items. Scientometrics, 66(2), 327-343.

Cartieri, F., \& Potochnik, A. (2014). Toward Philosophy of Science's Social Engagement. Erkenntnis, 79(5), 901-916. https://doi.org/10.1007/s10670-013-9535-3

Chalmers, D. J. (2015). Why Isn't There More Progress in Philosophy? Philosophy, 90(1), 331. https://doi.org/10.1017/S0031819114000436

Cherry, M. (2017). Coming out of the shade. In R. Blackford \& D. Broderick (Eds.), Philosophy's Future: The Problem of Philosophical Progress (pp. 21-30). John Wiley $\&$ Sons.

Chi, P.S. (2014). Which role do non-source items play in the social sciences? A case study in political science in Germany. Scientometrics, 101(2), 1195-1213.

Chi, P.S. (2015). Changing publication and citation patterns in political science in Germany. Scientometrics, 105(3), 1833-1848.

Cronin, B., Shaw, D., \& Barre, K. L. (2003). A cast of thousands: Coauthorship and subauthorship collaboration in the 20th century as manifested in the scholarly journal literature of psychology and philosophy. Journal of the American Society for Information Science and Technology, 54(9), 855-871. https://doi.org/10.1002/asi.10278

Dennett, D. C. (2006). Higher-order truths about chmess. Topoi, 25(1), 39-41. https://doi.org/10.1007/s11245-006-0005-2

Dewey, J. (2004). Democracy and Education. Dover Publications.

Dietrich E. There Is No Progress in Philosophy. Essays in Philosophy [Internet]. 2011 Jul 11;12(2). Available from: https://commons.pacificu.edu/eip/vol12/iss2/9

Dietrich, E. (2011). There Is No Progress in Philosophy. Essays in Philosophy, 12(2). https://commons.pacificu.edu/eip/vol12/iss2/9 
Engels, T. C. E., Ossenblok, T. L. B., \& Spruyt, E. H. J. (2012). Changing publication patterns in the social sciences and humanities, 2000-2009. Scientometrics, 93(2), 373390.

Fehr, C., \& Plaisance, K. S. (2010). Socially relevant philosophy of science: an introduction. Synthese, 177(3), 301-316. https://doi.org/10.1007/s11229-010-9855-7

Frodeman, R. (2013). Philosophy dedisciplined. Synthese, 190(11), 1917-1936. https://doi.org/10.1007/s11229-012-0181-0

Glänzel, W., Thijs, B., \& Chi, P. S. (2016). The challenges to expand bibliometric studies from periodical literature to monographic literature with a new data source: The Book Citation Index. Scientometrics, 109(3), 2165-2179.

Hicks, D. (1999). The difficulty of achieving full coverage of international social science literature and the bibliometric consequences. Scientometrics, 44(2), 193-215.

Higgins, A., \& Dyschkant, A. (2014). Interdisciplinary Collaboration in Philosophy. Metaphilosophy, 45(3), 372-398. https://doi.org/10.1111/meta.12091

Higgins, A., \& Smith, B. (2013). A Citation Based View of the Ontology Community in Philosophy. In Proceedings of the ACM Web Science 2013.

Kitcher, P. (2011). Philosophy Inside Out. Metaphilosophy, 42(3), 248-260. https://doi.org/10.1111/j.1467-9973.2011.01684.x

Klavans, R., \& Boyack, K. W. (2017a). Research portfolio analysis and topic prominence. Journal of Informetrics, 11(4), 1158-1174. https://doi.org/10.1016/j.joi.2017.10.002

Klavans, R., \& Boyack, K. W. (2017b). Which Type of Citation Analysis Generates the Most Accurate Taxonomy of Scientific and Technical Knowledge? Journal of the Association for Information Science and Technology, 68(4), 984-998. https://doi.org/10.1002/asi.23734

Kreuzman, H. (2001). A co-citation analysis of representative authors in philosophy: Examining the relationship between epistemologists and philosophers of science. Scientometrics, 50(3), 525-539. https://doi.org/10.1023/A:1012778307249

Ladyman, J. (2017). What has philosophy ever done for us? In R. Blackford \& D. Broderick (Eds.), Philosophy's Future: The Problem of Philosophical Progress (pp. 31-40). John Wiley \& Sons. 
McLevey, J., Graham, A. V., McIlroy-Young, R., Browne, P., \& Plaisance, K. S. (2018). Interdisciplinarity and insularity in the diffusion of knowledge: an analysis of disciplinary boundaries between philosophy of science and the sciences. Scientometrics, 117(1), 331-349. https://doi.org/10.1007/s11192-018-2866-8

Nederhof, A. J. (2006). Bibliometric monitoring of research performance in the social sciences and the humanities: A review. Scientometrics, 66(1), 81-100.

Petrovich, E., \& Buonomo, V. (2018). Reconstructing Late Analytic Philosophy. A Quantitative Approach. Philosophical Inquiries, 6(1), 151-182. https://doi.org/10.4454/philinq.v6i1.184

Pigliucci, M. (2017). Philosophy as the evocaton of conceptual landscapes. In R. Blackford \& D. Broderick (Eds.), Philosophy's Future: The Problem of Philosophical Progress (pp. 75-90). John Wiley \& Sons.

Plaisance, K. S. (2020). The benefits of acquiring interactional expertise: Why (some) philosophers of science should engage scientific communities. Studies in History and Philosophy of Science Part A. https://doi.org/10.1016/j.shpsa.2020.03.002

Plaisance, K. S., Graham, A. V., McLevey, J., \& Michaud, J. (2019). Show me the numbers: a quantitative portrait of the attitudes, experiences, and values of philosophers of science regarding broadly engaged work. Synthese. https://doi.org/10.1007/s11229019-02359-7

Plant, B. (2012). Philosophical Diversity and Disagreement. Metaphilosophy, 43(5), 567591. https://doi.org/10.1111/j.1467-9973.2012.01770.x

Rescher, N. (1985). The Strife of Systems: An Essay on the Grounds and Implications of Philosophical Diversity. University of Pittsburgh Press.

Sivertsen, G., \& Larsen, B. (2012). Comprehensive bibliographic coverage of the social sciences and humanities in a citation index: An empirical analysis of the potential. Scientometrics, 91(2), 567-575.

Tiberius, V. (2017). The well-being of philosophy. In Proceedings and Addresses of the American Philosophical Association, 91, 65-86.

Wilson, J. (2017). Three Barriers to Philosophical Progress. In R. Blackford \& D. Broderick (Eds.), Philosophy's Future: The Problem of Philosophical Progress (pp. 91-104). John Wiley \& Sons. 



\section{Appendix A. Criteria of selecting analysed research topics}

1. To ensure the quality of classification, we selected only research topics that have an active editor in Philpapers.

2. To ensure that statistical analysis is meaningful, we selected only research topics with at least 150 documents published since 1998 .

3. To ensure that the topics are devoted to a single research question, we excluded all topics of which the name indicates that they are heterogeneous, e.g. if they have 'miscellaneous' in their name.

4. To ensure that we could test the hypotheses outlined above, we selected topics from philosophy of science, philosophy of societal issues, and core philosophy. Philosophy of science-topics were selected from the following Philpapers Areas: 'Philosophy of Biology', 'Philosophy of the Physical sciences', and 'General Philosophy of Science'. Philosophy of societal issue-topics were selected from the following Philpaper Areas: 'Applied Ethics', 'Meta-Ethics', 'Normative Ethics', 'Philosophy of Race, Gender, and Sexuality', and 'Social and Political Philosophy'. Core philosophy topics were selected from the following Areas: 'Epistemology', 'Metaphysics', 'Philosophy of Language', 'Philosophy of Mind'. Within philosophy of science and societal issues, these areas were selected to include both topics close to core philosophy (e.g. metaethics) and topics further removed from it (e.g. applied ethics).

5. To ensure that we could test the hypotheses, we excluded topics that fall clearly in more than one of the three main philosophical areas. For example, topics that concern research integrity were excluded, and we did not select topics from 'philosophy of the cognitive sciences' to avoid overlap with 'philosophy of mind'.

6. To avoid overlap between topics, we avoided selecting two topics that are closely related. For example, we did not select both 'Teleology' and 'Functions' for philosophy of biology.

7. To ensure relatively wide coverage of the whole of analytic philosophy, we selected 6 topics from philosophy of science, 6 topics from philosophy of societal issues, and 5 topics from core philosophy.

8. Whenever the decision was not determined by other criteria, we ranked topics by the number of documents they contain. 


\section{Appendix B. Principles to distinguish philosophers on the basis of their corresponding addresses}

1. Identify all the authors from addresses that contain "PHIL", "FILO", "Pholosoph" or "ETH" (excluding "Method", country "Netherlands", and university "ETH") ${ }^{14}$ as philosophers.

2. Manually check and identify the authors with addresses showing only the main institution/university names without further department information.

3. Use the philosopher list collected from Step 1 and 2 to exclude the author names which were already known as philosophers.

4. Collect a keyword list of department names (see Appendix B.1) which are clearly not philosophical institutions from the result of Step 3, and identify the authors with these addresses as non-philosophers.

5. Manually check the authors of the remaining 31 papers by their affiliation addresses.

\section{B-1. Keywords for detecting non-philosophic addresses}

'\%Behav \%' OR '\%Evolutionsbiol\%' OR '\%Weather\%' OR '\%Anim Prod Syst\%' OR '\%Indigenous Knowledges\%' OR '\%Sustainabil\%' OR '\%Neurosci\%' OR '\%Informat Sci\%' OR '\%Policy\%' OR '\%Climate Sci\%' OR '\%Comparat\%' OR '\%Conservat Genet\%' OR '\%Gender\%' OR '\%Social Care\%' OR '\%Law\%' OR '\%Invest\%' OR '\%Media\%' OR '\%Mediterraneenne\%' OR '\%Latin\%' OR '\%Citizenship\%' OR '\%Urban\%' OR '\%Accounting\%' OR '\%Business\%' OR '\%Basic Sci\%' OR '\%Biol\%' OR '\%Commun\%' OR '\%Soil Sci\%' OR '\%Dev Sociol\%' OR '\%Earth\%' OR '\%Engn\%' OR '\%Environm\%' OR '\%Oncol\%' OR '\%Fis \%' OR '\%Geol\%' OR '\%Interact\%' OR '\%Manage\%' OR '\%Mat Sci\%' OR '\%Matemat\%' OR '\%Commun\%' OR '\%Mkt\%' OR '\%Obstet\%' OR '\%Organism\%' OR '\%Paediat\%' OR '\%Geosyst\%' OR '\%Probabil\%' OR '\%Psychol\%' OR '\%Publ Hlth\%' OR '\% Technol\%' OR '\%Semiot\%' OR '\%Sociol\%' OR '\%Social\%' OR '\%Zool\%' OR '\%Sci Fis\%' OR '\%Sociol\%' OR '\%Global\%' OR '\%Polytech\%' OR '\%Vet Med\%' OR '\%Hlth\%' OR '\%Math\%' OR '\%Brain\%' OR '\%Chem\%' OR '\%Coastal\%' OR '\%Marine\%' OR '\%Languages\%' OR '\%Quantum\%' OR '\% Theoret $\%$ ' OR '\% Transcultural\%' OR '\%Psycholinguist\%' OR '\%Nucl\%' OR '\%Polit\%' OR '\%Psychiat $\%$ ' OR '\%Neurosci\%' OR '\%Prevent\%' OR '\%Physiol\%' OR '\%Conservat\%' OR '\%Geosci\%' OR '\%Agr\%' OR '\%Mol $\%$ ' OR '\%Disabil\%' OR '\%Modeling\%' OR '\%Life\%' OR '\%IBISC\%' OR '\%CONICET\%' OR '\%Review\%' OR '\%Sch Econ\%'

\footnotetext{
14 The latter two exclusions were only initiated when there are on any above characters shown in other part of the address.
} 


\section{Appendix C. Detailed overview of eleven isolation indicators applied in this study}

\section{C-1. General isolation (Citgen, $\operatorname{Ref}_{\text {gen }}$, Imp $_{\text {gen }}$ )}

Indicator 1: What proportion of a topic's citations is from documents within the topic?

We measure the ratio of the times the papers in a topic are cited by papers in the topic to the total number of citations of papers in the topic as equation $\boldsymbol{C i t}_{\boldsymbol{g e n}}=\frac{\boldsymbol{C}_{\boldsymbol{t p}}}{\boldsymbol{C}_{T}}$, where $C_{T}$ is the total number of citations of the papers in a given topic, and $C_{t p}$ is the number of citations of those papers received from papers in the same topic. This indicator investigates the extent to which a topic's influence is isolated from academic work outside the topic. The higher a topic scores for this indicator, the more isolated it is.

Indicator 2: What proportion of a topic's references cite documents in the topic?

If a paper has a high ratio of references from documents in the same topic, it is likely that the authors rely to a great extent on ideas developed in that topic. In this sense, a topic's ratio of references from the same topic reflects the degree to which that topic is isolated from academic work outside the topic. We calculate the ratio of the times papers in a topic cite papers in their own topic to the total number of references of papers in the topic as equation $\boldsymbol{R} \boldsymbol{e} \boldsymbol{f}_{\boldsymbol{g e n}}=\frac{\boldsymbol{R}_{\boldsymbol{t} \boldsymbol{p}}}{\boldsymbol{R}_{\boldsymbol{T}}}$, where $R_{T}$ is the total number of references of the papers in a topic, and $R_{t p}$ is the number of references of the papers from other papers in the same topic.

Indicator 3: How often, on average, are the papers in a topic cited by papers from outside the topic?

We measure the ratio of the times the papers in a topic were cited by papers from outside the topic to the total number of the papers in the topic as equation $I \boldsymbol{I m} \boldsymbol{p}_{g e n}=\frac{\boldsymbol{C}_{T}-\boldsymbol{C}_{\boldsymbol{t p}}}{\boldsymbol{N}_{T}}$, where $C_{T}$ is the total number of citations of the topic, $C_{t p}$ is the number of citations from within the topic, and $N_{T}$ is the total number of papers in the topic. Note that for this indicator a low score indicates isolation: the more a topic is cited by papers outside the topic, the less isolated it is.

\section{C-2. Disciplinary isolation $\left(\right.$ Cit $\left._{\text {disc, }}, \operatorname{Ref}_{\text {disc, }}, \operatorname{Imp}_{\text {disc }}\right)$}

Indicator 4: What proportion of a topic's citations is from papers in philosophy?

We measure the ratio of the times the papers in a topic are cited by papers in philosophy to the total number of citations of the papers in the topic as formula $\boldsymbol{C i t}_{\text {disc }}=\frac{\boldsymbol{C}_{P}}{\boldsymbol{C}_{T}}$, where $C_{T}$ is the total number of citations of the topic, and $C_{P}$ is the number of philosophical papers citing those WoS papers.

Indicator 5: What proportion of a topic's references refers to papers in philosophy?

We measure the ratio of the times the papers in a topic cite papers in philosophy to the total number of references of all papers in the topic as equation $\boldsymbol{R} \boldsymbol{e} \boldsymbol{f}_{\boldsymbol{d i s c}}=\frac{\boldsymbol{R}_{\boldsymbol{P}}}{\boldsymbol{R}_{\boldsymbol{T}}}$, where $R_{T}$ is the total 
number of references in a topic, and $R_{P}$ is the number of references of the topic to philosophical papers.

Indicator 6: How often, on average, are papers in a topic cited by papers from outside the field?

We measure the ratio of the times the papers in a topic are cited by non-philosophical papers to the total number of the papers by the equation $\boldsymbol{I m} \boldsymbol{p}_{\text {disc }}=\frac{\boldsymbol{C}_{T}-C_{P}}{\boldsymbol{N}_{T}}$, where $C_{T}$ is the total number of citations of the topic, $C_{P}$ is the number of papers from philosophy citing the topic and $N_{T}$ is the total number of papers in the topic.

\section{C-3. Isolation from Philosophy (Cit $\left.t_{\text {phil, }} \operatorname{Ref}_{\text {phil, }} \operatorname{Imp}_{\text {phil }}\right)$}

Indicator 7: What proportion of a topic's philosophical citations is from papers in the topic?

To investigate the extent to which topics are isolated from other philosophical research, we measure the ratio of philosophical papers in the topic citing the papers in the topic to all philosophical papers citing the papers in the topic as equation $\boldsymbol{C i t}_{\boldsymbol{p h i l}}=\frac{\boldsymbol{C}_{\boldsymbol{P t p}}}{\boldsymbol{C}_{\boldsymbol{P}}}$, where $C_{P}$ is the total number of philosophical papers citing the papers in the topic, and $C_{P t p}$ is the number of philosophical citations of those papers from papers in the same topic.

Indicator 8: What proportion of a topic's philosophical references refers to papers in the same topic?

This indicator focuses on a topic's references to philosophical papers. We calculate the ratio of the times the papers in a topic cite philosophical papers in the topic to the total number of philosophical references of papers in the topic as equation $\boldsymbol{R} \boldsymbol{e} \boldsymbol{f}_{\boldsymbol{p h i l}}=\frac{\boldsymbol{R}_{\boldsymbol{P t p}}}{\boldsymbol{R}_{\boldsymbol{P}}}$, where $R_{P}$ is the total number of philosophical references of the papers in the topic, and $R_{P t p}$ is the number of philosophical references from the same topic.

Indicator 9: How often, on average, are the papers of a topic cited by philosophical papers outside the topic?

Similar to Indicator 3 and 6, we measure the extent to which a topic impacts philosophical work outside the topic by the ratio of the times the papers in a topic are cited by philosophical papers from outside the topic to the total number of the papers in the topic as equation $\boldsymbol{I m} \boldsymbol{p}_{\boldsymbol{p h i l}}=\frac{\boldsymbol{C}_{\boldsymbol{P}}-\boldsymbol{C}_{\boldsymbol{P t p}}}{\boldsymbol{N}_{\boldsymbol{T}}}$, where $C_{P}$ is the total number of philosophical papers citing the papers in a topic, $C_{P t p}$ is the number of citations of those papers from philosophical papers in the same topic, and $N_{T}$ is the total number of papers in the topic.

\section{C-4. Collaborative isolation $\left(\mathrm{Col}_{\sin }, \mathrm{Col}_{\text {disc }}\right)$}

Indicator 10: What proportion of papers are single-authored?

Unlike most other fields of academia, philosophers rarely write papers in collaboration with other researchers. Indeed, this may be one of the reasons for the isolation of philosophical 
research topics, as research that is done in collaboration is likely to be less isolated than singleauthored work. We therefore measure the ratio of the number of single-authored papers in a topic to the total number of the papers in that topic as equation

$\operatorname{Col}_{\sin }=\frac{N_{S}}{N_{T}}$, where $N_{T}$ is the total number of papers in a topic, and $N_{S}$ is the number of papers in that topic published by only one author.

Indicator 11: What proportion of papers are co-authored with non-philosophers?

We investigate how often the philosophers of a topic collaborate with non-philosophers. To do this, we measure the ratio of the number of the papers in a topic published by at least one philosopher and one non-philosopher to the total number of papers as equation

$\operatorname{Col}_{\text {disc }}=\frac{N_{C}}{N_{T}}$, where $N_{T}$ is the total number of papers in a topic, and $N_{C}$ is the number of papers in that topic co-published by at least one philosopher and one non-philosopher. Note that the collaborations between only philosophers or only non-philosophers are not included in $N_{C}$. 
Appendix D. Values of all the isolation indicators of 17 topics in three kinds of philosophy (2000-2017)

\begin{tabular}{|c|c|c|c|c|c|c|c|c|c|c|c|c|}
\hline \multirow{2}{*}{\multicolumn{2}{|c|}{ TOPIC }} & \multicolumn{3}{|c|}{ General isolation } & \multicolumn{3}{|c|}{ Disciplinary isolation } & \multicolumn{3}{|c|}{ Isolation from Philosophy } & \multicolumn{2}{|c|}{ Collaborative isolation } \\
\hline & & Cit $_{\text {gen }}$ & $\operatorname{Ref} f_{g e n}$ & Imp $p_{\text {gen }}$ & Cit ${ }_{\text {disc }}$ & $\boldsymbol{R e f} f_{\text {disc }}$ & $I m p_{\text {disc }}$ & Cit $_{\text {phil }}$ & $\operatorname{Ref}_{\text {phil }}$ & Imp $p_{\text {phil }}$ & Col $_{\text {sin }}$ & Col $_{\text {disc }}$ \\
\hline \multicolumn{2}{|c|}{ Philosophy of Science } & $8.6 \%$ & $8.7 \%$ & 10.1 & $37.4 \%$ & $33.8 \%$ & 6.9 & $17.3 \%$ & $19.1 \%$ & 3.4 & $\mathbf{7 5 . 8 \%}$ & $4.3 \%$ \\
\hline \multirow{2}{*}{ General PoS } & Theory change & $12.2 \%$ & $8.0 \%$ & 3.5 & $79.8 \%$ & $71.8 \%$ & 0.8 & $13.9 \%$ & $10.5 \%$ & 2.7 & $90.9 \%$ & $1.5 \%$ \\
\hline & The nature of models & $9.2 \%$ & $10.8 \%$ & 10.9 & $71.8 \%$ & $56.6 \%$ & 3.4 & $12.8 \%$ & $18.9 \%$ & 7.5 & $79.7 \%$ & $5.1 \%$ \\
\hline \multirow{4}{*}{ Applied PoS } & Functions & $16.1 \%$ & $11.8 \%$ & 8.8 & $50.8 \%$ & $45.6 \%$ & 5.1 & $22.4 \%$ & $21.3 \%$ & 4.1 & $72.5 \%$ & $3.3 \%$ \\
\hline & $\begin{array}{l}\text { Matematical structure of } \\
\text { Quantum Mechanics }\end{array}$ & $2.2 \%$ & $1.8 \%$ & 6.5 & $24.1 \%$ & $10.1 \%$ & 5.1 & $1.7 \%$ & $1.6 \%$ & 1.6 & $65.5 \%$ & $4.7 \%$ \\
\hline & Species & $8.4 \%$ & $11.7 \%$ & 19.9 & $19.7 \%$ & $27.2 \%$ & 17.4 & $28.1 \%$ & $25.2 \%$ & 3.1 & $84.7 \%$ & $4.5 \%$ \\
\hline & Symmetry in physics & $6.1 \%$ & $4.5 \%$ & 6.2 & $29.3 \%$ & $19.6 \%$ & 4.6 & $17.3 \%$ & $17.7 \%$ & 1.6 & $68.0 \%$ & $4.8 \%$ \\
\hline \multicolumn{2}{|c|}{ Philosophy of Value Issues } & $19.9 \%$ & $14.0 \%$ & 3.1 & $60.2 \%$ & $49.9 \%$ & 1.5 & $31.4 \%$ & $26.7 \%$ & 1.6 & $85.7 \%$ & $3.7 \%$ \\
\hline \multirow{2}{*}{ General PoVI } & Moral expressivism & $41.6 \%$ & $28.2 \%$ & 2.6 & $90.3 \%$ & $88.2 \%$ & 0.4 & $46.1 \%$ & $32.0 \%$ & 2.2 & $92.2 \%$ & $0.5 \%$ \\
\hline & The doctrine of dual effect & $27.1 \%$ & $16.0 \%$ & 2.7 & $74.1 \%$ & $59.1 \%$ & 1.0 & $34.5 \%$ & $26.8 \%$ & 1.8 & $90.1 \%$ & $3.3 \%$ \\
\hline \multirow{4}{*}{$\begin{array}{l}\text { Applied } \\
\text { PoVI }\end{array}$} & Abortion & $10.5 \%$ & $10.1 \%$ & 3.7 & $52.7 \%$ & $41.2 \%$ & 1.9 & $19.8 \%$ & $24.2 \%$ & 1.7 & $83.5 \%$ & $5.5 \%$ \\
\hline & Animal rights & $8.7 \%$ & $5.5 \%$ & 2.8 & $33.6 \%$ & $18.9 \%$ & 2.0 & $15.6 \%$ & $14.7 \%$ & 0.9 & $82.2 \%$ & $5.3 \%$ \\
\hline & Moral status of animals & $9.5 \%$ & $7.1 \%$ & 3.7 & $69.2 \%$ & $53.3 \%$ & 1.3 & $12.8 \%$ & $13.4 \%$ & 2.5 & $81.3 \%$ & $2.5 \%$ \\
\hline & Rape and sexual violence & $5.1 \%$ & $3.4 \%$ & 3.5 & $14.9 \%$ & $10.0 \%$ & 3.2 & $23.4 \%$ & $21.3 \%$ & 0.4 & $82.4 \%$ & $4.7 \%$ \\
\hline \multicolumn{2}{|c|}{ Core Philosophy } & $40.4 \%$ & $30.1 \%$ & 2.9 & $92.4 \%$ & $93.0 \%$ & 0.4 & $42.7 \%$ & $32.3 \%$ & 2.6 & $90.1 \%$ & $0.4 \%$ \\
\hline \multirow{5}{*}{$\mathrm{CP}$} & Closure of knowledge & $29.4 \%$ & $15.6 \%$ & 2.4 & $94.5 \%$ & $88.2 \%$ & 0.2 & $31.1 \%$ & $17.7 \%$ & 2.2 & $88.0 \%$ & $1.1 \%$ \\
\hline & $\begin{array}{l}\text { Minimalism and deflationism } \\
\text { about truth }\end{array}$ & $41.0 \%$ & $16.0 \%$ & 1.4 & $93.1 \%$ & $95.1 \%$ & 0.2 & $42.4 \%$ & $16.9 \%$ & 1.3 & $90.9 \%$ & $0.0 \%$ \\
\hline & The exclusion problem & $39.1 \%$ & $34.4 \%$ & 4.3 & $91.0 \%$ & $94.7 \%$ & 0.6 & $41.8 \%$ & $36.3 \%$ & 3.7 & $91.5 \%$ & $0.0 \%$ \\
\hline & Truthmakers & $49.4 \%$ & $45.8 \%$ & 3.0 & $97.2 \%$ & $98.1 \%$ & 0.2 & $50.3 \%$ & $46.7 \%$ & 2.8 & $89.1 \%$ & $0.9 \%$ \\
\hline & $\begin{array}{l}\text { Zombies and the } \\
\text { conceivability argument }\end{array}$ & $20.3 \%$ & $14.1 \%$ & 3.2 & $78.0 \%$ & $75.8 \%$ & 0.9 & $23.9 \%$ & $18.0 \%$ & 2.4 & $89.9 \%$ & $0.0 \%$ \\
\hline
\end{tabular}


Appendix E. Citation and reference related indicators and citation impact of three levels of isolation

E-1. Citation and reference related indicators and citation impact of general isolation in three kinds of philosophy $(2000-2017)$

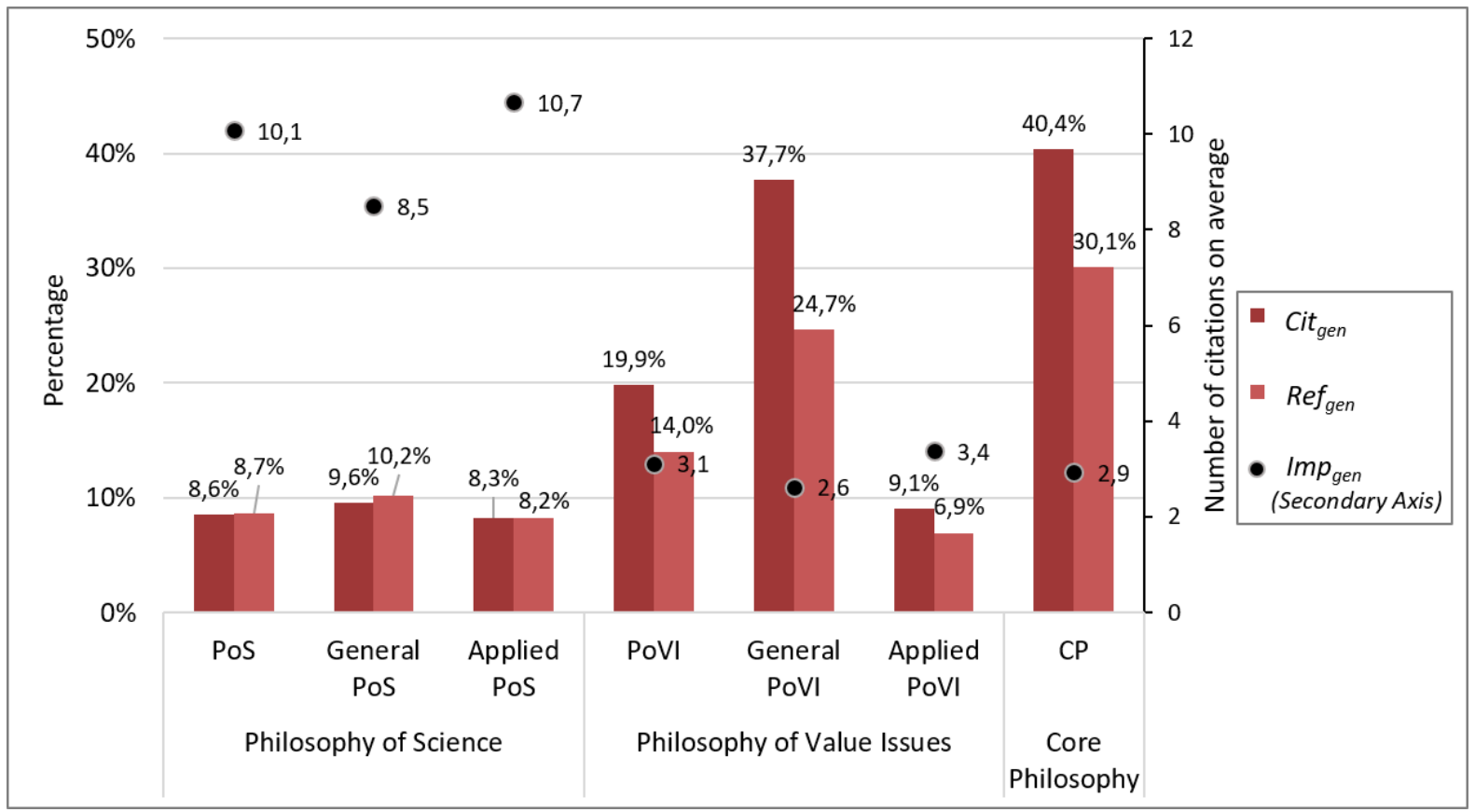

E-2. Citation and reference related indicators and citation impact of disciplinary isolation in three kinds of philosophy (2000-2017)

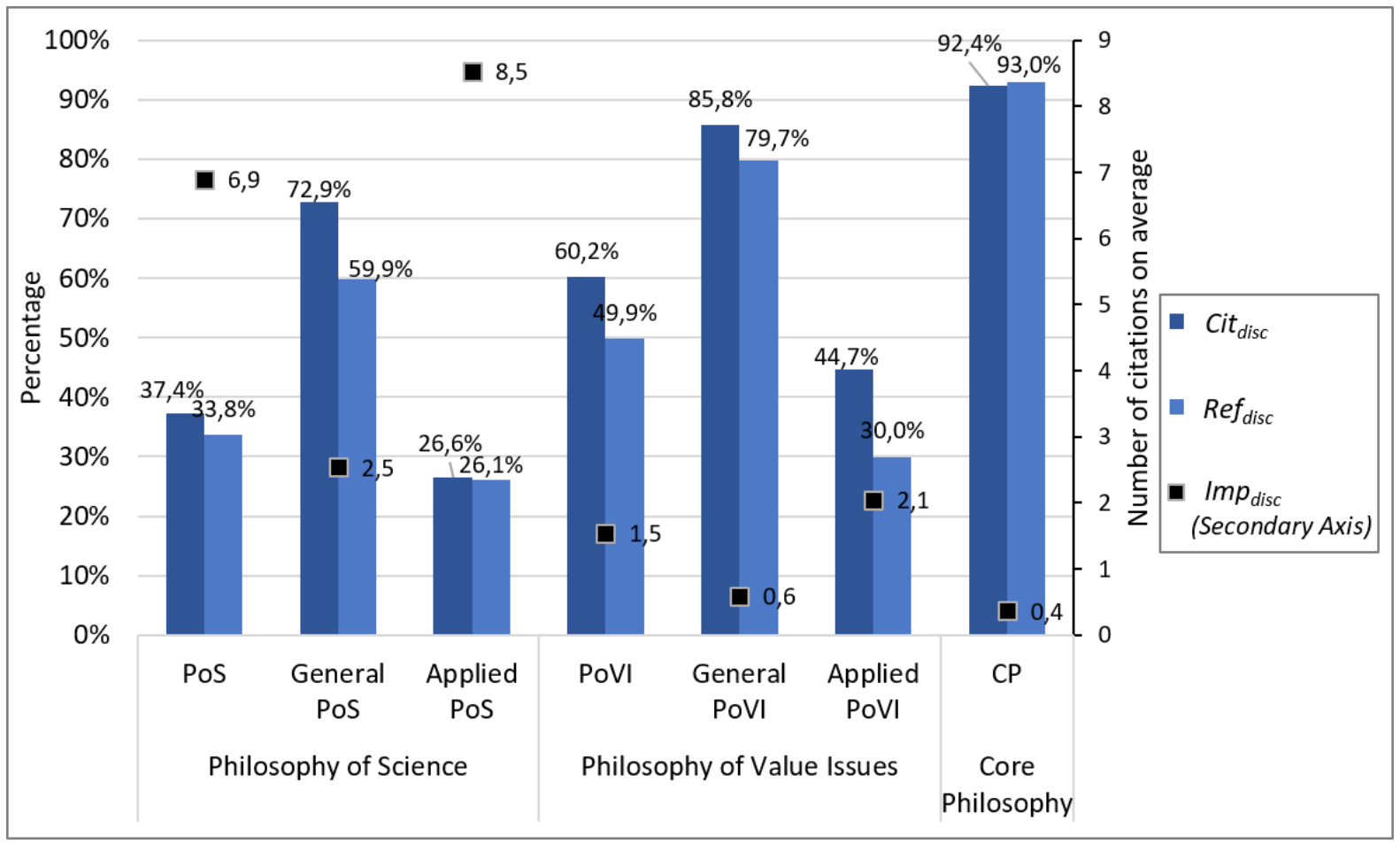


E-3. Citation and reference related indicators and citation impact of isolation from Philosophy in three kinds of philosophy (2000-2017)

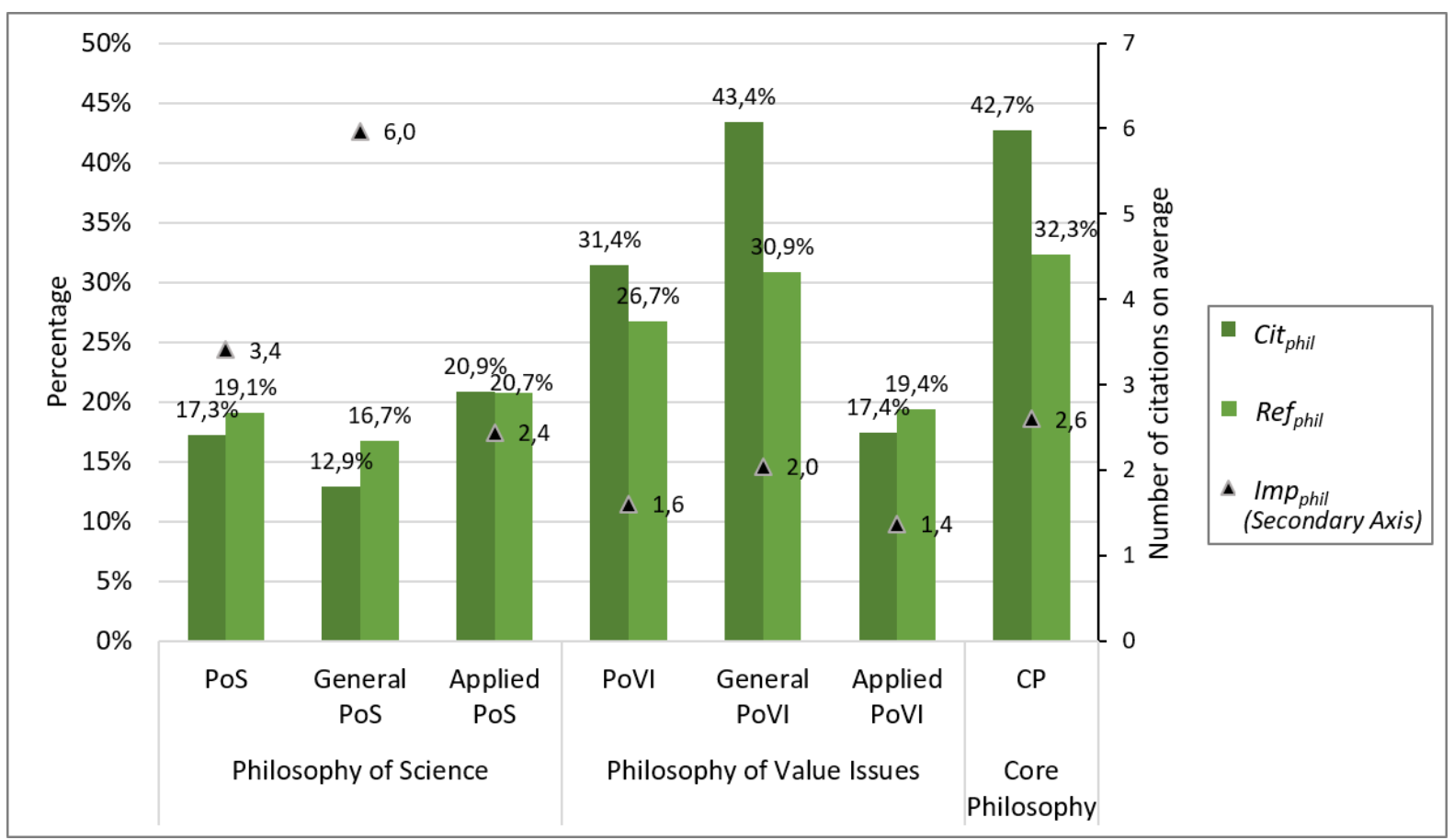


